\title{
MAX-DOAS observations of the total atmospheric water vapour column and comparison with independent observations
}

\author{
T. Wagner, M. O. Andreae, S. Beirle, S. Dörner, K. Mies, and R. Shaiganfar \\ Max Planck Institute for Chemistry, Hahn-Meitner-Weg 1, 55128 Mainz, Germany \\ Correspondence to: T. Wagner (thomas.wagner@mpic.de) \\ Received: 11 August 2012 - Published in Atmos. Meas. Tech. Discuss.: 3 September 2012 \\ Revised: 27 December 2012 - Accepted: 3 January 2013 - Published: 30 January 2013
}

\begin{abstract}
We developed an algorithm for the retrieval of the atmospheric water vapour column from Multi-AXis Differential Optical Absorption Spectroscopy (MAX-DOAS) observations in the yellow and red spectral range. The retrieval is based on the so-called geometric approximation and does not depend on explicit a priori information for individual observations, extensive radiative transfer simulations, or the construction of large look-up tables. Disturbances of the radiative transfer due to aerosols and clouds are simply corrected using the simultaneously measured absorptions of the oxygen dimer, $\mathrm{O}_{4}$. We applied our algorithm to MAXDOAS observations made at the Max Planck Institute for Chemistry in Mainz, Germany, from March to August 2011, and compared the results to independent observations. Good agreement with Aerosol Robotic Network (AERONET) and European Centre for Medium-Range Weather Forecasting (ECMWF) $\mathrm{H}_{2} \mathrm{O}$ vertical column densities (VCDs) is found, while the agreement with satellite observations is less good, most probably caused by the shielding effect of clouds for the satellite observations. Good agreement is also found with near-surface in situ observations, and it was possible to derive average daily $\mathrm{H}_{2} \mathrm{O}$ scale heights (between $1.5 \mathrm{~km}$ and $3 \mathrm{~km}$ ). MAX-DOAS measurements use cheap and simple instrumentation and can be run automatically. One important advantage of our algorithm is that the $\mathrm{H}_{2} \mathrm{O}$ VCD can be retrieved even under cloudy conditions (except clouds with very high optical thickness).
\end{abstract}

\section{Introduction}

Water vapour is the most important natural greenhouse gas. Its atmospheric concentration increases strongly with temperature, and the resulting increase in the atmospheric water vapour content is expected to further amplify climate change (water vapour feedback, see e.g. Held and Soden, 2000, and references therein, Solomon et al., 2007). Water vapour is also important for meridional transport of latent heat, it determines the global distribution of clouds, and it plays an important role in many chemical reactions. In contrast to most other greenhouse gases, the atmospheric water vapour distribution is highly variable. Thus, measurements of atmospheric water vapour on various spatial and temporal scales are important.

There is a large variety of in situ and remote sensing techniques for the measurement of water vapour that can be operated from different platforms (ground based, aircraft and balloon borne, space borne). From these observations the water vapour concentration, altitude profiles, or (partial) columns can be retrieved. Here we present a new method for analysing the vertically integrated water vapour concentration, the so-called vertical column density (VCD), from Multi-AXis Differential Optical Absorption Spectroscopy (MAX-DOAS) observations. The $\mathrm{H}_{2} \mathrm{O}$ VCD is often referred to as total column precipitable water (expressed e.g. as $\mathrm{g} \mathrm{cm}^{-2}$ ) in the meteorological literature: $1 \mathrm{~g} \mathrm{~cm}^{-1}$ equals roughly $3.3 \times 10^{22}$ molecules $\mathrm{cm}^{-2}$.

MAX-DOAS instruments observe scattered sun light at various slant elevation angles and allow the retrieval of concentration profiles or column densities of several tropospheric trace gases, for example, $\mathrm{NO}_{2}, \mathrm{HCHO}$ or $\mathrm{BrO}$ (e.g. Hönninger and Platt, 2002; Van Roozendael et al., 2003; 
Wittrock et al., 2004; Wagner et al., 2004; Brinksma et al., 2008, and references therein). The first retrievals of $\mathrm{H}_{2} \mathrm{O}$ concentration profiles were recently presented by Irie et al. (2011), using the $\mathrm{H}_{2} \mathrm{O}$ absorption band at $506 \mathrm{~nm}$. Here we follow a different strategy: our main aim is a simple and stable algorithm that does not depend on explicit a priori and external information for individual observations. We use the $\mathrm{H}_{2} \mathrm{O}$ absorption bands in the yellow and red spectral range, which are about one order of magnitude larger than those at $506 \mathrm{~nm}$. Instead of retrieving a vertical concentration profile, our algorithm yields the integrated atmospheric column density. The information content of a column density is of course less than that of a vertical profile. However, as shown below, the $\mathrm{H}_{2} \mathrm{O}$ VCD is highly correlated with the surface concentration. Furthermore, the $\mathrm{H}_{2} \mathrm{O}$ VCD is a very useful quantity (e.g. for meteorological applications and the validation of satellite observations).

\section{Instrument and data analysis}

\subsection{Instrument and measurement conditions}

MAX-DOAS observations at the Max Planck Institute for Chemistry (MPIC) in Mainz, Germany $\left(50.0^{\circ} \mathrm{N}, 8.27^{\circ} \mathrm{E}\right)$ were carried out from 19 March to 30 August 2011. The period of measurements covered different meteorological conditions, with temperatures ranging from about 0 to $35^{\circ} \mathrm{C}$ and thus largely varying atmospheric $\mathrm{H}_{2} \mathrm{O}$ VCDs. The measurements were performed using a Mini-MAX-DOAS instrument (Bobrowski et al., 2003; Ibrahim et al., 2010) covering the spectral range from $500 \mathrm{~nm}$ to $800 \mathrm{~nm}$ with a spectral resolution of about $1 \mathrm{~nm}$ (full width at half maximum, FWHM). Measurements were carried out between sunrise and sunset using an automated routine (based on the DOASIS software, see Kraus, 2006) with typical integration times of about $1 \mathrm{~min}$. Since the instrument was mounted directly in front of a window (see Fig. 1), the viewing angles were restricted by the roof (and also by opposite buildings) to a range between $15^{\circ}$ and $70^{\circ}$ (the selected sequence of elevation angles was $15^{\circ}, 20^{\circ}, 30^{\circ}, 60^{\circ}, 70^{\circ}$ ). The time for a full sequence of elevation angles was typically about $7 \mathrm{~min}$ (including the movement of the stepper motor to change the elevation angles). The azimuth angle of the telescope was $74^{\circ}$ with respect to north. Besides instrumental problems, on several individual days and during a longer period between 5 May and 16 June, the instrument was operated almost continuously; in total more than 40000 individual spectra were recorded.

\subsection{Spectral analysis}

The measured spectra are analysed using the DOAS method (Platt and Stutz, 2008). Two separate wavelength intervals with relatively strong $\mathrm{H}_{2} \mathrm{O}$ absorption bands were selected:

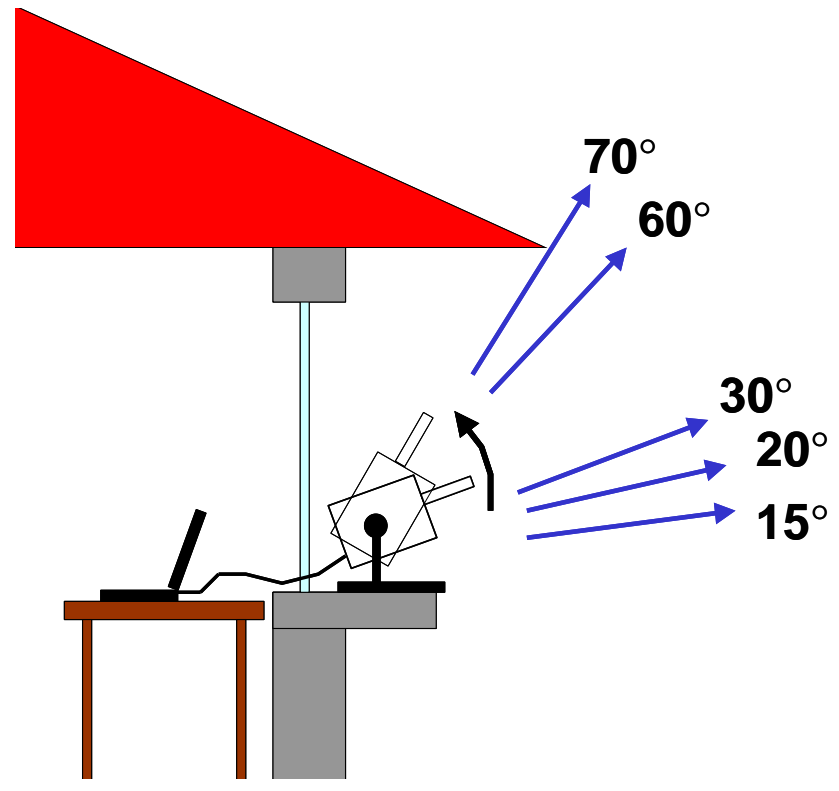

Fig. 1. Instrumental set-up at the Max Planck Institute for Chemistry, Mainz, Germany. A Mini-MAX-DOAS instrument was placed in front of a window. It was protected from rain by the roof of the building. But this roof also restricted the highest possible elevation angle to $70^{\circ}$. The lowest elevation angle $\left(15^{\circ}\right)$ was determined by the height of opposite buildings.

a. $608-680 \mathrm{~nm}$. Besides the $\mathrm{H}_{2} \mathrm{O}$ absorption, it also contains absorption bands of the oxygen molecule $\left(\mathrm{O}_{2}\right)$ and the oxygen dimer $\left(\mathrm{O}_{4}\right)$.

b. $543-620 \mathrm{~nm}$. Besides the $\mathrm{H}_{2} \mathrm{O}$ absorption it also contains an $\mathrm{O}_{4}$ absorption band.

In addition to the reference spectra for these species and ozone (see Table 1), a Fraunhofer reference spectrum, a Ring spectrum (calculated from the Fraunhofer reference spectrum) and a low order polynomial were included in the spectral analysis (using the WinDOAS software, Fayt and van Roozendael, 2001). A spectrum measured at $70^{\circ}$ elevation angle on 26 March 2011 at 13:13 UTC $\left(\right.$ SZA $\left.=52.3^{\circ}\right)$ was used as Fraunhofer reference spectrum for the whole experiment. The wavelength calibration was performed based on a high resolution solar spectrum (Kurucz et al., 1984). Typical fit results are shown in Fig. 2. Note that including also a reference spectrum for the atmospheric $\mathrm{NO}_{2}$ absorptions has only a very small influence (typically $<1 \%$ ) on the results for $\mathrm{O}_{4}$ and $\mathrm{H}_{2} \mathrm{O}$.

The output of the spectral analysis is the slant column density (SCD), which is the integrated trace gas concentration along the effective light path through the atmosphere. Besides $\mathrm{H}_{2} \mathrm{O}$, the SCDs of $\mathrm{O}_{2}$ and $\mathrm{O}_{4}$ are also used for further processing (see below). From the spectral analysis, the uncertainty of the retrieved SCDs are also determined; for the SCDs of $\mathrm{H}_{2} \mathrm{O}, \mathrm{O}_{2}$, and $\mathrm{O}_{4}$ it is typically $<10 \%$. 
Table 1. Settings used for the spectral analysis.

\begin{tabular}{|c|c|c|}
\hline Spectrum & Source & Preparation \\
\hline \multicolumn{3}{|c|}{ (A) Analysis in the red spectral range $(608-680 \mathrm{~nm})$} \\
\hline $\mathrm{H}_{2} \mathrm{O}$ cross section & $\begin{array}{l}\text { HITRAN data base } \\
\text { (Rothman et al., 2005) }\end{array}$ & $\begin{array}{l}\text { convolution to match } \\
\text { spectral resolution of } \\
\text { the instrument }\end{array}$ \\
\hline $\mathrm{O}_{2}$ cross section & $\begin{array}{l}\text { HITRAN data base } \\
\text { (Rothman et al., 2005) }\end{array}$ & $\begin{array}{l}\text { convolution to match } \\
\text { spectral resolution of } \\
\text { the instrument }\end{array}$ \\
\hline $\mathrm{O}_{4}$ cross section & Greenblatt et al. (1990) & interpolation \\
\hline Ring spectrum & $\begin{array}{l}\text { calculated from Fraunhofer } \\
\text { reference spectrum using } \\
\text { the DOASIS software } \\
\text { (Kraus, 2006) }\end{array}$ & \\
\hline \multicolumn{3}{|c|}{ Polynomial of 4 th order } \\
\hline \multicolumn{3}{|c|}{ (B) Analysis in the yellow spectral range $(543-620 \mathrm{~nm})$} \\
\hline $\mathrm{H}_{2} \mathrm{O}$ cross section & $\begin{array}{l}\text { HITRAN data base } \\
\text { (Rothman et al., 2005) }\end{array}$ & $\begin{array}{l}\text { convolution to match } \\
\text { spectral resolution of } \\
\text { the instrument }\end{array}$ \\
\hline $\mathrm{O}_{4}$ cross section & Greenblatt et al. (1990) & interpolation \\
\hline $\mathrm{O}_{3}$ cross section & 221K, (Burrows et al., 1999) & $\begin{array}{l}\text { convolution to match } \\
\text { spectral resolution of } \\
\text { the instrument }\end{array}$ \\
\hline Ring spectrum & $\begin{array}{l}\text { calculated from Fraunhofer } \\
\text { reference spectrum using } \\
\text { the DOASIS software } \\
\text { (Kraus, 2006) }\end{array}$ & \\
\hline Polynomial of $3 \mathrm{rc}$ & & \\
\hline
\end{tabular}

Since a measured spectrum is used as Fraunhofer reference, the retrieved results represent the difference of the SCDs between the measurement at low elevation angle $\alpha$ and the Fraunhofer reference spectrum, the so called differential SCD or DSCD:

$\mathrm{DSCD}_{\alpha}=\mathrm{SCD}_{\alpha}-\mathrm{SCD}_{\text {Fraunhofer }}$.

Because $\mathrm{H}_{2} \mathrm{O}$ and $\mathrm{O}_{4}$ are retrieved in both spectral ranges, a decision had to be made which analysis should be used for further processing. To answer this question, we compared the results of both spectral ranges. They are very similar, but small differences were also found, especially with respect to the scatter of subsequent data points on clear days. For such conditions, it is expected that the diurnal variation of the retrieved DSCDs should show a smooth behaviour. The results for one selected clear day are shown in Fig. 3. For $\mathrm{H}_{2} \mathrm{O}$, less scatter is found for the wavelength interval $608-680 \mathrm{~nm}$. In contrast, for $\mathrm{O}_{4}$ less scatter is found for the wavelength interval $543-620 \mathrm{~nm}$. These findings are also confirmed by the average fit errors of the whole measurement series for both spectral ranges: for $\mathrm{O}_{4}$ the average fit errors are $8.4 \times 10^{41} \mathrm{molec}^{5} \mathrm{~cm}^{-2}$ and $15.3 \times 10^{41} \mathrm{molec}^{5} \mathrm{~cm}^{-2}$ in the green and red spectral range, respectively; for $\mathrm{H}_{2} \mathrm{O}$ the average fit errors are $1.61 \times 10^{21} \mathrm{molec} \mathrm{cm}^{-2}$ and $1.55 \times$ $10^{21}$ molec cm${ }^{-2}$ in the green and red spectral range, respectively. Thus, in the following for $\mathrm{O}_{4}$ the fit results from the green spectral range, and for $\mathrm{H}_{2} \mathrm{O}$ those from the red spectral range are used.

\subsection{Conversion to the atmospheric vertical column density (VCD)}

From the retrieved DSCDs, the vertically integrated trace gas concentration, the so called vertical column density (VCD) is calculated according to the following formula (Wagner et al., 2010):

$\mathrm{VCD}_{\alpha, \beta}=\frac{\mathrm{DSCD}_{\alpha}-\mathrm{DSCD}_{\beta}}{\mathrm{AMF}_{\alpha}-\mathrm{AMF}_{\beta}}$.

Here, $\mathrm{DSCD}_{\alpha}$ and $\mathrm{DSCD}_{\beta}$ refer to the retrieved DSCDs for low $(\alpha)$ and high $(\beta)$ elevation angles (Eq. 1) of an individual elevation sequence. $\mathrm{AMF}_{\alpha}$ and $\mathrm{AMF}_{\beta}$ are the respective air mass factors (AMF). The air mass factor describes the ratio between the SCD and VCD:

$\mathrm{AMF}=\mathrm{SCD} / \mathrm{VCD}$

The AMFs used in this study are calculated by the so called geometric approximation (Brinksma et al., 2008; Shaiganfar et al., 2011). For MAX-DOAS observations of tropospheric trace gases, the geometric approximation of the AMF is determined from simple geometric considerations:

$\mathrm{AMF}_{\text {geometric }}=1 / \sin (\alpha)$.

The geometric approximation is adequate for measurements, for which the effective atmospheric light path through the trace gas layer can be well described by a straight line. This is typically fulfilled for measurements at large wavelengths and for low aerosol loads. While the first condition is fulfilled for our MAX-DOAS measurements, the effect of aerosol scattering can potentially have a strong influence on some days (for more details see Sect. 2.4).

The VCDs of $\mathrm{H}_{2} \mathrm{O}$ and $\mathrm{O}_{4}$ retrieved from the 6 different combinations of low $\left(15^{\circ}, 20^{\circ}, 30^{\circ}\right)$ and high elevation angles $\left(60^{\circ}, 70^{\circ}\right)$ are shown in Fig. 3. Both for $\mathrm{H}_{2} \mathrm{O}$ and $\mathrm{O}_{4}$, the VCDs for the different combinations show similar values. Nevertheless, for further processing of the $\mathrm{H}_{2} \mathrm{O}$ VCDs we used the combination of $20^{\circ}$ and $70^{\circ}$, because the $\mathrm{O}_{4} \mathrm{VCDs}$ derived from this combination of elevation angles showed the lowest scatter (see Table 2). Of course, for future studies using different azimuth and elevation angles, other combinations of elevation angles might be favourable.

Note that the $\mathrm{O}_{4} \mathrm{VCD}$ is usually expressed in the unit [ $\mathrm{molec}^{2} \mathrm{~cm}^{-5}$ ], because the equilibrium constant between $\mathrm{O}_{4}$ and $\left(\mathrm{O}_{2}\right)_{2}$ is not known. Therefore, the $\mathrm{O}_{4} \mathrm{VCD}$ usually refers to the integrated quadratic $\mathrm{O}_{2}$ concentration (see also Greenblatt et al., 1990).

Since the $\mathrm{H}_{2} \mathrm{O}$ absorption fine structure is not fully resolved by our measurements, the $\mathrm{H}_{2} \mathrm{O}$ SCDs derived from the spectral analysis are not a linear function of the true atmospheric $\mathrm{H}_{2} \mathrm{O}$ SCDs. We correct this "saturation effect" by simulating the non-linearity as described in Wagner et al. (2003). In the following, the corrected $\mathrm{H}_{2} \mathrm{O}$ DSCDs are used for the determination of the $\mathrm{H}_{2} \mathrm{O}$ VCD (Eq. 2). It 

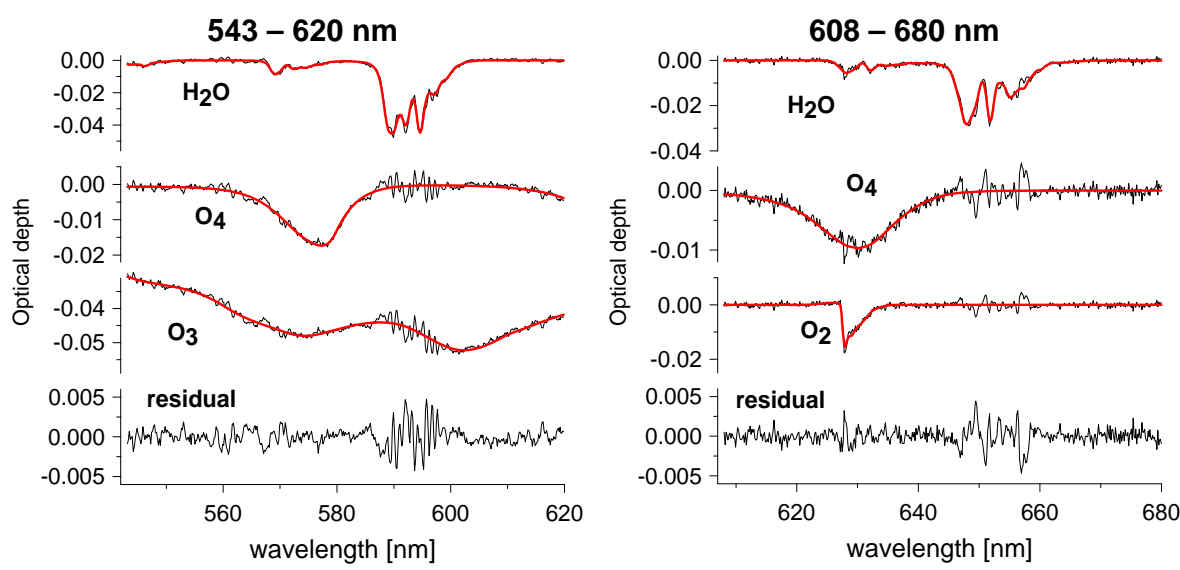

Fig. 2. Typical result of the DOAS fit in both spectral windows. Shown are the cross-sections (red) scaled to the respective absorption in the measured spectrum (black). Observations are from 4 April 2011, 08:30 for an elevation angle of $20^{\circ}$ and a solar zenith angle of 58.0 ${ }^{\circ}$.

should, however, be noted that for the $\mathrm{H}_{2} \mathrm{O}$ VCDs retrieved from our observations, the saturation effect is typically well below $10 \%$ (see bottom panel of Fig. 3). Our saturation correction assumes a constant AMF for all wavelengths and, thus, does not take into account the wavelength dependence of the AMF, mainly caused by the varying strengths of the individual absorption lines (Pukite et al., 2009). We quantified the resulting underestimation assuming an extreme situation with a high $\mathrm{H}_{2} \mathrm{O}$ VCD $\left(1.8 \times 10^{23}\right.$ molec cm$\left.^{-2}\right)$ and without aerosol and cloud scattering using high resolution radiative transfer simulations. The corresponding underestimation is about $7 \%$; typical values for smaller $\mathrm{H}_{2} \mathrm{O}$ VCDs are about $3 \%$. Compared to other uncertainties (see Sect. 2.8) this error is neglected in this study.

\subsection{Radiative transfer simulations}

In this section we investigate the validity of the geometric approximation for our MAX-DOAS retrievals. For this purpose we performed radiative transfer simulations using the Monte-Carlo model MCARTIM (Monte Carlo atmospheric radiative transfer model) (Deutschmann et al., 2011).

For the standard simulations, we used a $\mathrm{H}_{2} \mathrm{O}$ profile with a scale height of $2 \mathrm{~km}$ and an $\mathrm{O}_{4}$ profile with a scale height of $4 \mathrm{~km}$. The assumption of a scale height of $2 \mathrm{~km}$ for the $\mathrm{H}_{2} \mathrm{O}$ profile is roughly confirmed by the comparison of the retrieved $\mathrm{H}_{2} \mathrm{O}$ VCDs and simultaneous in situ measurements of the $\mathrm{H}_{2} \mathrm{O}$ concentration at the surface (see Sect. 3.7). We quantified the influence of deviations of the $\mathrm{H}_{2} \mathrm{O}$ scale height from $2 \mathrm{~km}$ on the retrieved $\mathrm{H}_{2} \mathrm{O}$ VCDs using radiative transfer simulations: for scale heights between $1.5 \mathrm{~km}$ and $3 \mathrm{~km}$ the deviations are below $15 \%$. In $95 \%$ of all cases between March and August 2011, the scale heights of the $\mathrm{H}_{2} \mathrm{O}$ profiles above Mainz fall within that range.

To study the effect of aerosols, we assumed different aerosol extinction profiles and calculated the respective AMFs of $\mathrm{H}_{2} \mathrm{O}$ and $\mathrm{O}_{4}$ for various combinations of elevation angles (EA), relative azimuth angles (RAZI) and solar zenith angles (SZA). The results for a SZA of $50^{\circ}$ are shown in Fig. 4 (similar results are found for other SZA between $20^{\circ}$ and $80^{\circ}$ ). In the upper part of the figure, the AMFs simulated for EA of $20^{\circ}$ and $70^{\circ}$ are shown. The bottom part shows the ratio of the AMF differences $\left(20^{\circ}\right.$ minus $\left.70^{\circ}\right)$ between the radiative transfer simulations and the geometric approximation. Deviations of this ratio from unity reflect systematic errors caused by the geometric approximation.

For aerosol-free conditions, the VCDs retrieved using the geometric approximation underestimate the true atmospheric VCDs by about $10 \%$ and $30 \%$ for $\mathrm{H}_{2} \mathrm{O}$ and $\mathrm{O}_{4}$, respectively. However, in the presence of aerosol scattering, the underestimation can become much stronger, especially for small RAZI. This underestimation is caused by the additional aerosol scattering, which leads to a decrease of the direct light path through the trace gas layer and, thus, to a reduced AMF for low elevation angles. Because of the higher atmospheric scale height, this effect has a stronger influence on the $\mathrm{O}_{4}$ AMFs.

\subsection{Correction using observations of the oxygen dimer $\mathrm{O}_{4}$}

As demonstrated in the previous section, the errors of the $\mathrm{H}_{2} \mathrm{O}$ VCD due to the geometric approximation can be quite large, especially for high aerosol loads and for measurements made at small RAZI (for our measurements, RAZI within $\pm 50^{\circ}$ occur between 04:00 and 10:30).

One possibility for correcting these errors would be to use appropriate AMFs derived from radiative transfer simulations instead of AMFs calculated by the geometric approximation. However, such calculations are complicated because typically the atmospheric aerosol extinction profile is not known, and clouds also strongly affect the atmospheric radiative transfer. 
$543-620 \mathrm{~nm}$

A) $\mathrm{O}_{4} \mathrm{DSCD}$

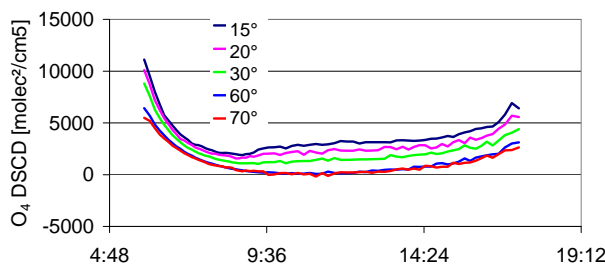

B) $\mathrm{H}_{2} \mathrm{O}$ DSCD

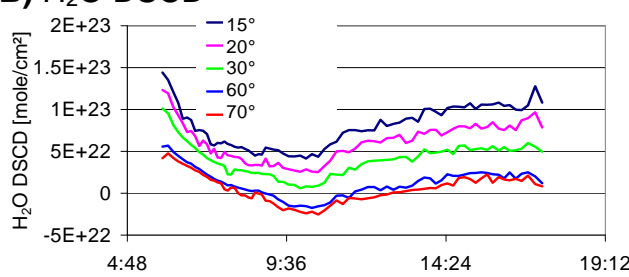

C) $\mathrm{O}_{4} \mathrm{VCD}$

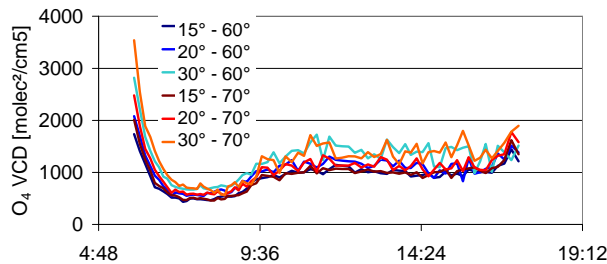

D) $\mathrm{H}_{2} \mathrm{O} \vee C D$

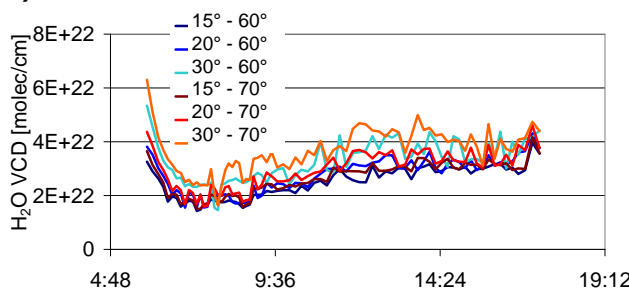

E) $\mathrm{H}_{2} \mathrm{O}$ VCD (saturation corrected)

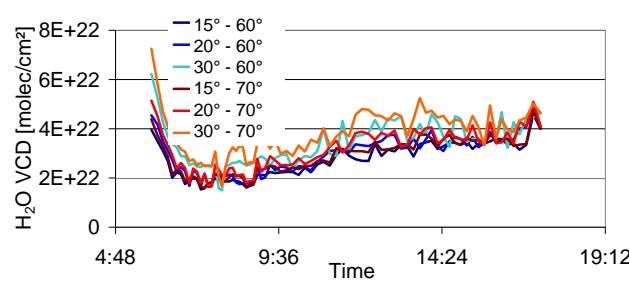

$608-680 \mathrm{~nm}$
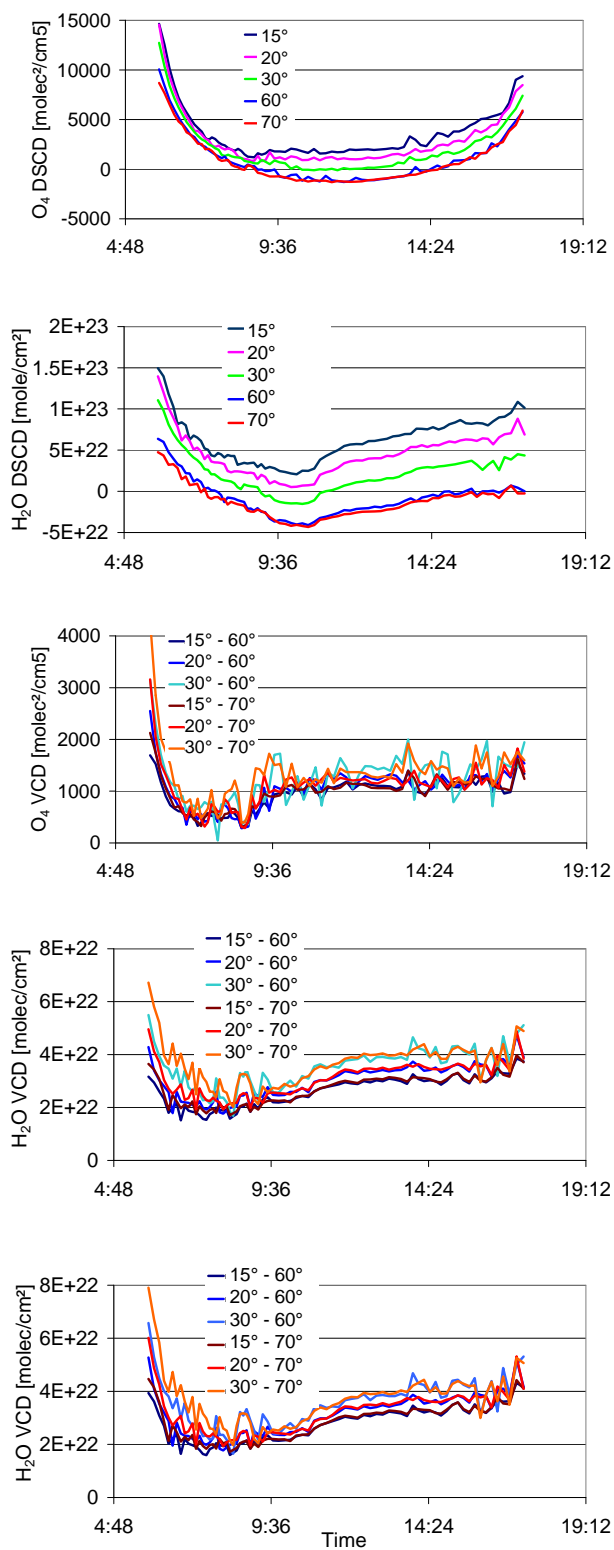

Fig. 3. DSCDs (A and B) and VCDs (C, D and E) of $\mathrm{H}_{2} \mathrm{O}$ and $\mathrm{O}_{4}$ retrieved on a clear day (23 March 2011) in the yellow spectral range (left) and red spectral range (right). The VCDs are calculated from different combinations of high and low elevation angles using the geometric approximation. For $\mathrm{H}_{2} \mathrm{O}$, a saturation correction (see text) was applied.

Because of these difficulties, we followed a different approach: we continued using the geometric approximation, but in order to correct for the effects of aerosols (and clouds) we used the simultaneously retrieved $\mathrm{O}_{4}$ VCDs (also based on the geometric approximation). Since the atmospheric $\mathrm{O}_{4}$ VCD is almost constant (small changes of a few percent are caused by variations of temperature and pressure), deviations of the retrieved $\mathrm{O}_{4} \mathrm{VCD}$ indicate deviations of the geometric approximation from the true atmospheric AMFs.

We calculated a correction factor $F_{\text {corr }}$ containing two terms:
- The first term is the ratio of the retrieved $\mathrm{O}_{4} \mathrm{VCD}$ and the true atmospheric $\mathrm{O}_{4} \mathrm{VCD}$ (for our measurement location we calculated a $\mathrm{O}_{4} \mathrm{VCD}$ of $1.3 \times$ $10^{40} \mathrm{molec}^{2} \mathrm{~cm}^{-5}$ from typical temperature and pressure profiles).

- The second term accounts for the general difference in sensitivity of MAX-DOAS retrievals using the geometric approximation for $\mathrm{H}_{2} \mathrm{O}$ and $\mathrm{O}_{4}$. For low aerosol loads and/or large RAZI, the ratio of the respective sensitivities for $\mathrm{H}_{2} \mathrm{O}$ and $\mathrm{O}_{4}$ (see Fig. 5) is about 1.25. 

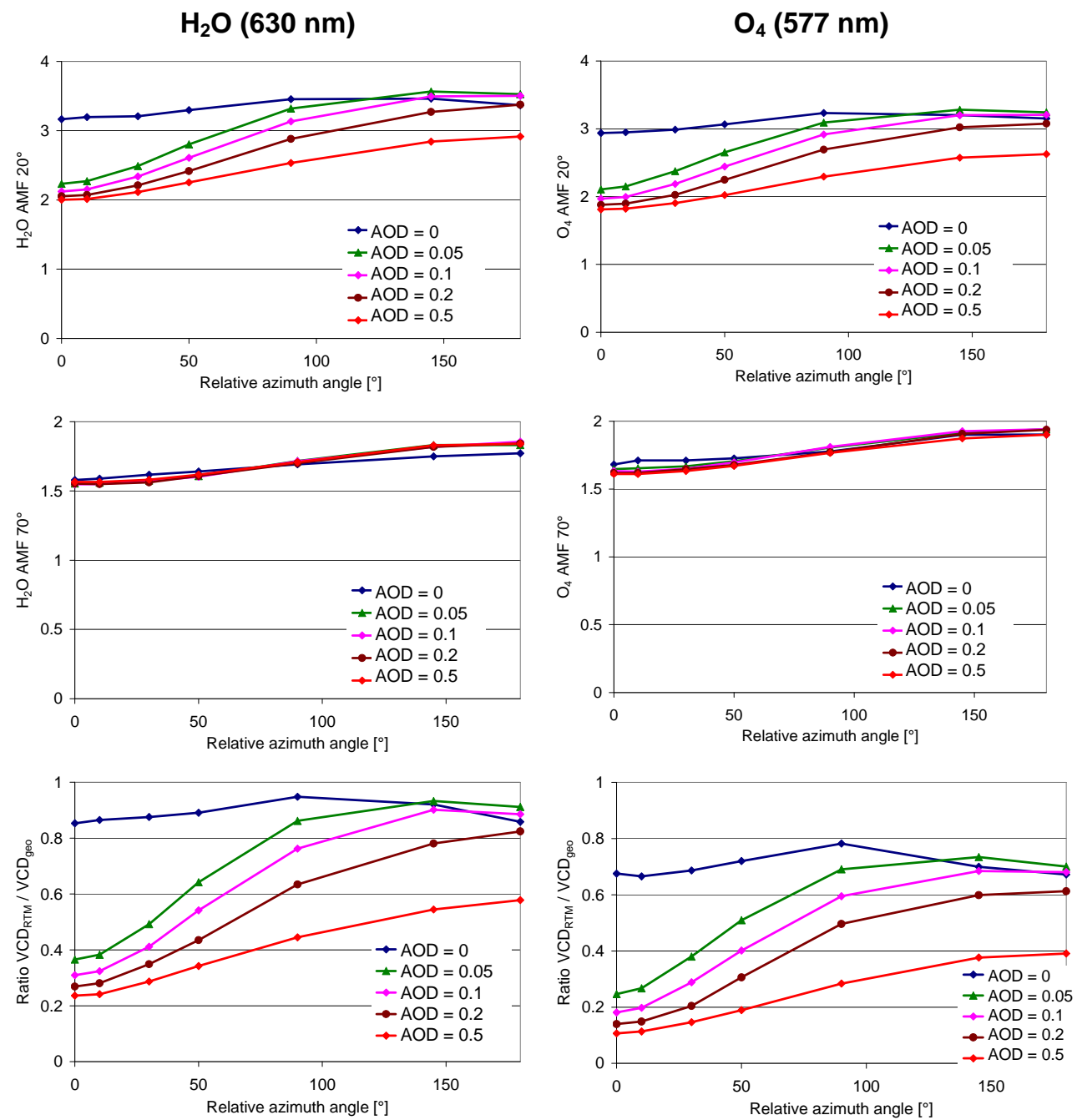

Fig. 4. Results of radiative transfer simulations for $\mathrm{H}_{2} \mathrm{O}$ (scale height of $2 \mathrm{~km}$, left) and $\mathrm{O}_{4}$ (scale height of $4 \mathrm{~km}$, right) for different aerosol loads. Top: AMFs for an elevation angle of $20^{\circ}$ as function of the RAZI. Middle: AMFs for an elevation angle of $70^{\circ}$ as function of the RAZI. Bottom: ratio of simulated AMF-differences $\left(20^{\circ}\right.$ minus $\left.70^{\circ}\right)$ and those using the geometric approximation. This ratio describes the underestimation of the true VCDs by retrievals based on the geometric approximation. The aerosol layer was assumed to have constant extinction between the surface and $1 \mathrm{~km}$. The solar zenith angle is $50^{\circ}$.

Similar correction factors (ranging from 1.20 to 1.30 ) are found for the other possible combinations of the elevation angles used in our measurements. Thus for the correction factor $F_{\text {corr }}$ we obtain

$F_{\text {corr }}=1.25 \cdot \frac{\mathrm{VCD}_{\mathrm{O}_{4}, \text { geometric }}}{\mathrm{VCD}_{\mathrm{O}_{4}, \text { true }}}$.

The final $\mathrm{H}_{2} \mathrm{O}$ VCD product from our MAX-DOAS observations is determined from the $\mathrm{H}_{2} \mathrm{O}$ VCD geometric (Eq. 2) retrieved using the geometric approximation by multiplication with this correction factor:

$\mathrm{VCD}_{\mathrm{H}_{2} \mathrm{O}}=F_{\text {corr }} \cdot \mathrm{VCD}_{\mathrm{H}_{2} \mathrm{O} \text {, geometric }}$.

For most cases shown in Figs. 4 and 5, the $\mathrm{H}_{2} \mathrm{O}$ VCDs retrieved in this way will be close to the true atmospheric $\mathrm{H}_{2} \mathrm{O}$
VCDs. However, for observations with high aerosol load (especially for small RAZI), large deviations from the true atmospheric $\mathrm{H}_{2} \mathrm{O}$ VCD can occur (see Fig. 5). To avoid such errors in the final $\mathrm{H}_{2} \mathrm{O}$ data set, we calculate the relative difference of the retrieved $\mathrm{O}_{4} \mathrm{VCD}$ from the true $\mathrm{O}_{4} \mathrm{VCD}$ :

$\Delta \mathrm{O}_{4}=\left(\mathrm{VCD}_{\mathrm{O}_{4}, \text { measured }}-\mathrm{VCD}_{\mathrm{O}_{4}, \text { true }}\right) / \mathrm{VCD}_{\mathrm{O}_{4}, \text { true }}$.

We excluded all $\mathrm{H}_{2} \mathrm{O}$ VCDs, for which $\Delta \mathrm{O}_{4}$ exceeded $\pm 30 \%$.

Using this criterion, not only measurements affected by high aerosol loads, but also by clouds (see below) are identified and removed. Of course, the threshold of $30 \%$ is chosen rather arbitrarily (from visible inspection of measurements affected by cloud and aerosol effects). Future studies might use more sophisticated selection criteria. 
Table 2. Standard deviation of the $\mathrm{O}_{4}$ VCD relative to the average $\mathrm{O}_{4} \mathrm{VCD}$ (in \%) derived from different combinations of elevation angles and wavelength ranges for the whole campaign.

\begin{tabular}{lcccccc}
\hline Elevation angles & $15^{\circ}, 60^{\circ}$ & $20^{\circ}, 60^{\circ}$ & $30^{\circ}, 60^{\circ}$ & $15^{\circ}, 70^{\circ}$ & $20^{\circ}, 70^{\circ}$ & $30^{\circ}, 70^{\circ}$ \\
\hline $\begin{array}{l}\text { Wavelength range } \\
\text { 543-620 nm }\end{array}$ & 0.24 & 0.22 & 0.37 & 0.22 & 0.17 & 0.30 \\
\hline $\begin{array}{l}\text { Wavelength range } \\
\text { 608-680 nm }\end{array}$ & 0.34 & 0.34 & 0.57 & 0.33 & 0.32 & 0.50 \\
\hline
\end{tabular}

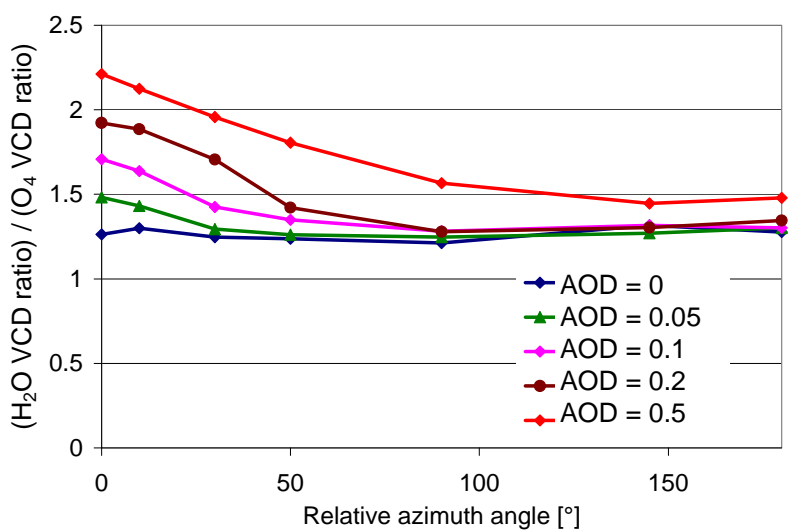

Fig. 5. Ratio of the relative deviation of the geometric approximation for $\mathrm{H}_{2} \mathrm{O}$ and $\mathrm{O}_{4}$ (see Fig. 4 bottom). A value of 1.25 is used to correct the retrieved $\mathrm{H}_{2} \mathrm{O}$ VCDs (see text).

From all measurements (elevation sequences), $54 \%$ fulfilled the $\mathrm{O}_{4}$ criterium while $46 \%$ showed deviations $>30 \%$ and were omitted. Here it is interesting to note that the fraction of skipped measurements is very similar for measurements under clear skies and thin clouds (for details of the cloud classification see Sect. 2.7), while most of the measurements under "thick" clouds are removed by this criterion.

The processing steps described in this section are illustrated for one clear and one cloudy day in Fig. 6. On the clear day, strong deviations from the geometric approximation are present for the morning observations (made at small RAZI). On the cloudy day, strong deviations from the geometric approximation occur, which are caused by the diffusing screen effect and the multiple scattering effect of clouds (for details see Sect. 2.6). After correction using the measured $\mathrm{O}_{4} \mathrm{VCDs}$ (Eq. 6), part of these deviations are corrected. In the final $\mathrm{H}_{2} \mathrm{O}$ VCD data set (bottom panel of Fig. 6) the observations not fulfilling the $\mathrm{O}_{4}$ criterion are removed, and the remaining data show a consistent diurnal cycle.

In Fig. 7 the daily averaged $\mathrm{H}_{2} \mathrm{O}$ VCDs during the whole measurement period are shown. The blue symbols show measurements that fulfil the $\mathrm{O}_{4}$ criterion; the red symbols show measurements that do not fulfil the $\mathrm{O}_{4}$ criterion. As expected, the latter show much larger scatter than the measurements that fulfil the $\mathrm{O}_{4}$ criterion.

\subsection{Effects of clouds}

Like aerosols, clouds can also strongly affect the atmospheric radiative transfer and thus the MAX-DOAS observations. Two main effects are especially important for MAX-DOAS observations: the so-called diffusing screen effect and the multiple scattering effect (see Wagner et al., 2011).

The diffusion screen effect describes the fact that under cloudy skies a substantial fraction of the photons received by the MAX-DOAS instrument has been directly scattered from the cloud bottom (instead from air molecules). This effect is especially important at large wavelengths and leads to both, a slight increase of the sensitivity for trace gases below the cloud, and a loss of sensitivity for trace gases above the cloud bottom.

Thus, for trace gases like $\mathrm{H}_{2} \mathrm{O}$ and $\mathrm{O}_{4}$, for which a considerable fraction of the total atmospheric column usually resides above the cloud bottom, the diffusing screen effect typically leads to an underestimation of the true atmospheric column density. The strength of this underestimation depends on the altitude of the cloud bottom and is, in general, larger for $\mathrm{O}_{4}$ than for $\mathrm{H}_{2} \mathrm{O}$ because of the larger scale height of $\mathrm{O}_{4}$. In Fig. 8, results from radiative transfer simulations of the diffusing screen effect for $\mathrm{H}_{2} \mathrm{O}$ and $\mathrm{O}_{4}$ are shown (similar to the simulations of the aerosol effects shown in Figs. 4 and 5). These simulations are performed for an assumed cloud with vertical thickness of $1 \mathrm{~km}$ and an optical thickness of 5 . The cloud bottom is assumed to be at 2,5 , or $9 \mathrm{~km}$.

In the upper row of Fig. 8 the ratio of the simulated AMF differences $\left(20^{\circ}-70^{\circ}\right)$ and those from the geometric approximation is shown. Values $<1$ indicate an underestimation and $>1$ an overestimation of the true atmospheric VCDs. For $\mathrm{H}_{2} \mathrm{O}$, only low clouds lead to a systematic underestimation of the true VCD. For high clouds, the increase of the direct light path below the cloud is the dominant effect and even causes a slight overestimation. In contrast, for $\mathrm{O}_{4}$, low and mid-level clouds cause a systematic underestimation of the true $\mathrm{O}_{4} \mathrm{VCD}$ of up to $50 \%$. The bottom row of Fig. 8 shows the ratio of the deviations of geometric approximations for $\mathrm{H}_{2} \mathrm{O}$ and $\mathrm{O}_{4}$ (similar to Fig. 5). For all scenarios, values $>1$ are found indicating that the diffusing screen effect leads to an overestimation of the $\mathrm{H}_{2} \mathrm{O}$ VCD retrieved by Eq. (6).

Multiple scattering becomes important for vertically extended clouds with large optical depth. Under such 
(mostly) clear day (23 March 2011)
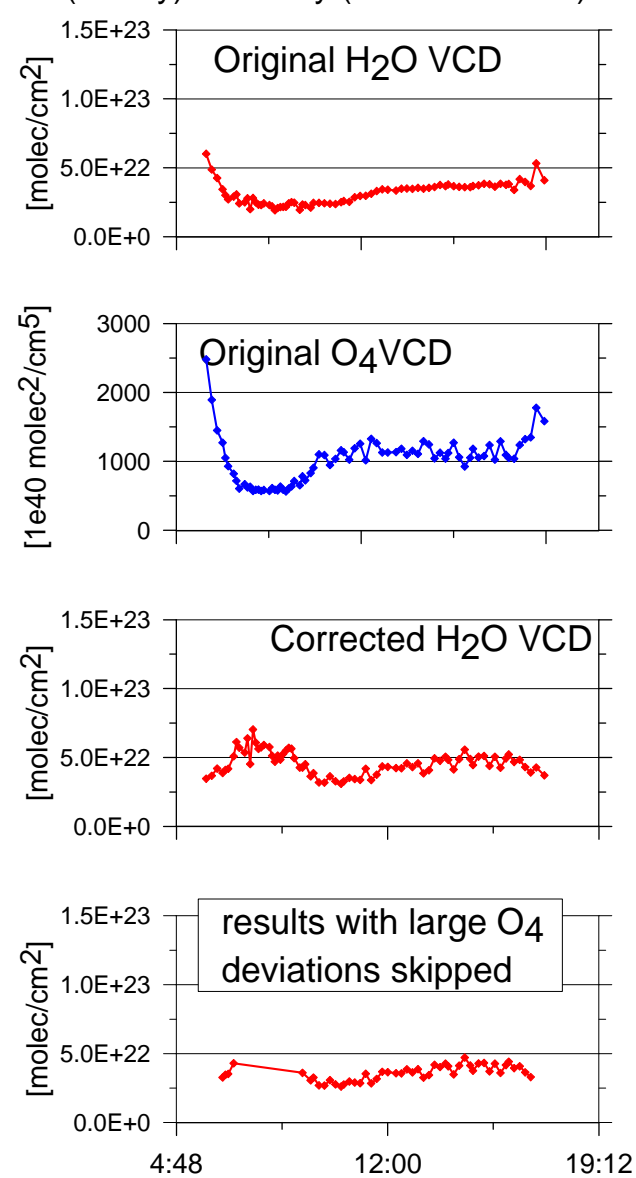
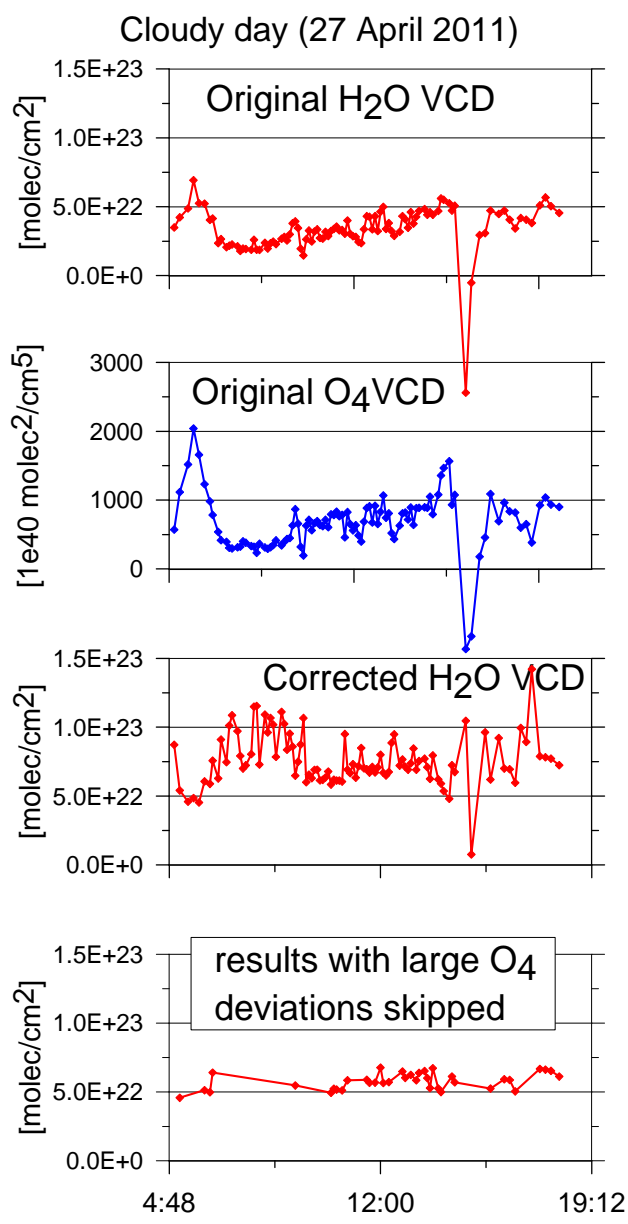

Fig. 6. Illustration of the different processing steps to correct for atmospheric radiative effects for a clear day (left) and cloudy day (right): the two upper rows show the retrieved $\mathrm{VCDs}$ of $\mathrm{H}_{2} \mathrm{O}$ and $\mathrm{O}_{4}$, for which the influence of aerosols and clouds can lead to large deviations from the true atmospheric VCDs. The third row shows the $\mathrm{H}_{2} \mathrm{O}$ VCDs calculated according to Eq. (6). For these $\mathrm{H}_{2} \mathrm{O}$ VCDs part of the aerosol and cloud effects are corrected. However, especially for the cloudy day, strong and unrealistic variations remain. After applying a filter based on the retrieved $\mathrm{O}_{4}$ VCDs (see text), the most deviating measurements are removed (bottom row). $\mathrm{H}_{2} \mathrm{O}$ column densities are displayed in red colour, $\mathrm{O}_{4}$ column densities are displayed in blue colour.

conditions, the light path lengths inside the clouds can become very long (up to more than $100 \mathrm{~km}$, e.g. Erle et al., 1995; Wagner et al., 1998; Winterrath et al., 1999). Since a substantial fraction of $\mathrm{H}_{2} \mathrm{O}$ and $\mathrm{O}_{4}$ is typically present inside the cloud, the respective absorptions can become strongly increased compared to clear sky conditions. Especially in the case of rapidly varying cloud cover, the multiple scattering effect can lead to strong positive or negative deviations of the retrieved $\mathrm{H}_{2} \mathrm{O}$ VCD from the true atmospheric VCDs. Examples of both cloud effects (diffusing screen effect and multiple scattering effect) are shown in Fig. 10 (details will be discussed in Sect. 2.7). The influence of clouds on the VCDs of $\mathrm{H}_{2} \mathrm{O}$ and $\mathrm{O}_{4}$ can also be seen in Fig. 6 (right panel).

\subsection{Characterisation of cloud properties during the measurement period}

We performed a simple characterisation of the influence of clouds based on the measured MAX-DOAS spectra. The results of this characterisation are verified using satellite images from the MODIS instrument (from the AERONET Data synergy tool, http://aeronet.gsfc.nasa.gov/ cgi-bin/bamgomas_interactive). Three categories are distinguished (see also Wagner et al., 2011):

a. clear skies,

b. thin clouds (main effect is the diffusing screen effect),

c. thick clouds (main effect is the multiple scattering effect). 


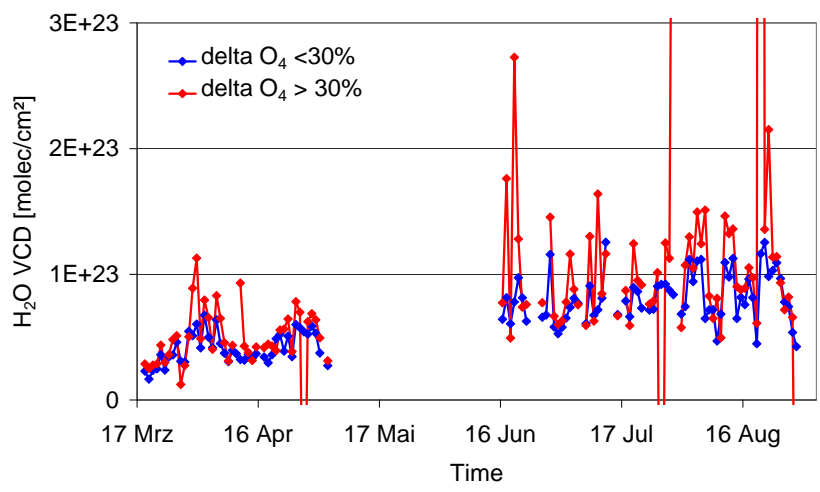

Fig. 7. Daily averaged $\mathrm{H}_{2} \mathrm{O}$ VCDs derived from MAX-DOAS observations. Blue symbols indicate measurements which fulfil the $\mathrm{O}_{4}$ criterion; red symbols indicate measurements which do not fulfil the $\mathrm{O}_{4}$ criterion (see text).

To assign a given measurement to one of the three categories, we used a similar scheme as presented in Wagner et al. (2011). Since for our MAX-DOAS measurements no zenith observations are available, we used observations at $70^{\circ}$ elevation angle instead. This, however, complicates the cloud classification, because the observed quantities not only depend on the SZA but also on the RAZI. Thus, no unique parameterization of threshold values for the observed quantities as a function of the SZA is possible, and we slightly modified the procedure described in Wagner et al. (2011): first, we did not apply a threshold to the observed normalised radiance to identify "thick clouds", because the radiance at $70^{\circ}$ elevation largely depends also on the RAZI. Instead, the classification of thick clouds is entirely based on the $\mathrm{O}_{4}$ observations.

Second, we quantified temporal variations of the radiance from the high-pass filtered diurnal variation: we linearly interpolated the radiances of the preceding and the subsequent measurements and subtracted it from the radiance of the actual measurements. In this way systematic variations caused by changes of the SZA and RAZI can be separated from short term variations caused by clouds.

Third, we used a higher threshold for the normalised $\mathrm{O}_{4}$ AMF (1 instead of 0.7), because of the (moderate) dependence of the $\mathrm{O}_{4}$ AMF on the RAZI. The modified cloud discrimination scheme is shown in Fig. 9.

According to this characterisation scheme, $38 \%$ of all measurements were classified as clear sky observations and $44 \%$ and $18 \%$ as observations under thin and thick clouds, respectively. While the first part of the time series (MarchMay) had many (partly) clear days, the second part (JuneAugust) was mostly cloudy. Here it should be noted that in the first version of our manuscript (Wagner et al., 2012), we had identified the different categories in a more qualitative way by visual inspection using the observations of $\mathrm{O}_{4}, \mathrm{H}_{2} \mathrm{O}$, $\mathrm{O}_{2}$ as well as the radiance and a colour index (see Fig. 10).
While this categorisation was to some degree subjective, it allowed to detect a substantially larger number of thin cloud cases (which were classified as clear by the less sensitive, automatic discrimination scheme used in the revised version of our manuscript). Future cloud classification schemes should use zenith sky observations, for which more strict and universal thresholds for various cloud sensitive parameters can be applied. However, the comparisons with independent observations (Sect. 3.6) were only slightly affected.

One example for a (mostly) clear day (23 March 2011) is shown in Fig. 10 (left). While the diurnal variations of the DSCDs of $\mathrm{H}_{2} \mathrm{O}$ and $\mathrm{O}_{2}$ still show some scatter, the radiance, the colour index, and the $\mathrm{O}_{4}$ DSCDs show a rather smooth variation (except towards the end of the day). At the bottom of Fig. 10 satellite images from the MODIS instrument are shown, indicating mostly clear skies around Mainz (blue circle) for 23 March 2011.

In the right part of Fig. 10 an example of a mostly cloudy day is shown (27 April 2011). Between about 09:00 and 15:00 the DSCDs of $\mathrm{H}_{2} \mathrm{O}, \mathrm{O}_{4}$ and $\mathrm{O}_{2}$ as well as the radiance and the colour index show rapid temporal variations indicating the presence of "thin" clouds (diffusing screen effect). Around 15:30 a strong increase is found for the measured DSCDs, indicating strongly enhanced multiple scattering caused by "thick" clouds. The presence of an optically thick cloud is confirmed by the minimum of the measured radiance. Also in the MODIS image on that day an extended cloud system is seen.

\subsection{Error budget of the derived $\mathrm{H}_{2} \mathrm{O} \mathrm{VCD}$}

The uncertainty of the $\mathrm{H}_{2} \mathrm{O}$ VCD product is dominated by two main error sources.

a. Uncertainties of the spectral analysis: The uncertainty of the fitting process is typically below $<3 \%$ and $10 \%$ for the DSCDs of $\mathrm{H}_{2} \mathrm{O}$ and $\mathrm{O}_{4}$, respectively. Since in the final $\mathrm{H}_{2} \mathrm{O}$ product both quantities are used, we take into account the higher value of $10 \%$.

In addition to the mostly random errors of the fitting process, also systematic uncertainties of the used cross sections affect the retrieved DSCDs. However, for the $\mathrm{H}_{2} \mathrm{O}$ and $\mathrm{O}_{4}$ cross sections these systematic uncertainties are difficult to quantify and we neglect them in the following. They affect all retrieved $\mathrm{H}_{2} \mathrm{O}$ VCDs in the same (multiplicative) way and can, for example, be determined by comparing the retrieved $\mathrm{H}_{2} \mathrm{O}$ VCDs with independent data sets (see Sect. 3.6). From the comparison with ECMWF model results and AERONET observations, we conclude that these systematic uncertainties (combined uncertainty of both cross sections) are probably below $10 \%$, but, of course, also other systematic errors of the MAX-DOAS retrieval or of the external data sets might contribute to the observed differences. 

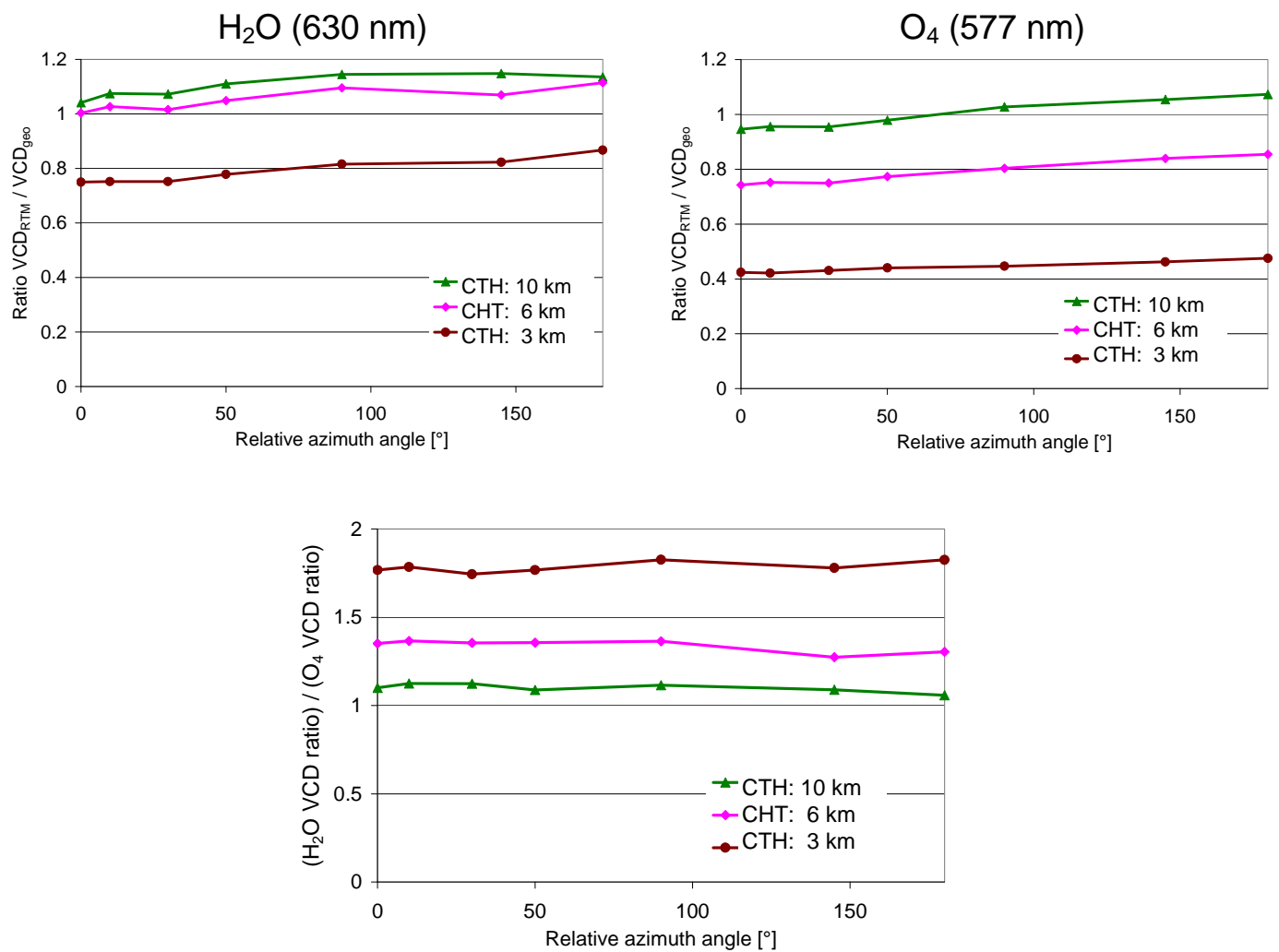

Fig. 8. Diffusing screen effect of clouds on the retrieval of the $\mathrm{H}_{2} \mathrm{O}$ VCD (top left) and the $\mathrm{O}_{4} \mathrm{VCD}$ (top right) determined by the geometric approximation as a function of the relative azimuth angle. Bottom: ratio of the diffusing screen effect for $\mathrm{H}_{2} \mathrm{O}$ and $\mathrm{O}_{4}$. The radiative transfer simulations were performed for a SZA of $50^{\circ}$. The cloud optical and vertical thicknesses were set to 5 and $1 \mathrm{~km}$, respectively.

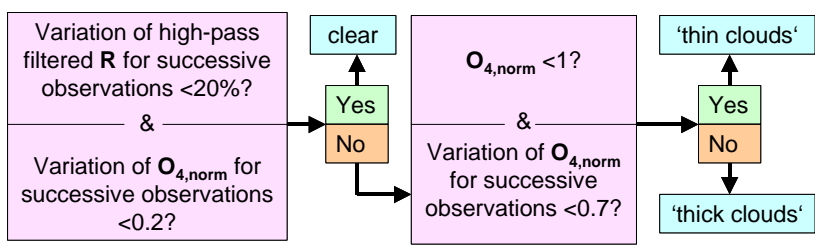

Fig. 9. Cloud classification scheme used in this study.

b. Uncertainties related to the atmospheric radiation transfer: In this study we applied AMFs calculated based on the geometric approximation. In reality, atmospheric scattering by molecules, but in particular also by aerosol and cloud particles, can lead to large deviations of these AMFs from the true AMFs. We account for these deviations by application of a correction factor considering the different scale heights of $\mathrm{H}_{2} \mathrm{O}$ and $\mathrm{O}_{4}$ and the different wavelength ranges of the respective fitting ranges. Several effects (variations of the $\mathrm{H}_{2} \mathrm{O}$ scale height, additional scattering by aerosols and cloud particles) can lead to deviations of this correction factor from the standard value. From radiative transfer simulations varying the above mentioned quantities, we find that these deviations are largely proportional to the deviation of the retrieved $\mathrm{O}_{4} \mathrm{VCD}$ from the true $\mathrm{O}_{4} \mathrm{VCD}\left(\Delta \mathrm{O}_{4}\right.$, see Eq. 7). Also, they are almost independent from SZA between SZA of $20^{\circ}$ and $80^{\circ}$. For measurements with $\Delta \mathrm{O}_{4}<30 \%$, the uncertainties of the retrieved $\mathrm{H}_{2} \mathrm{O}$ SCD are $<27 \%$. Thus, we use the amount of $\Delta \mathrm{O}_{4}$ to quantify the errors related to deviations of the true AMFs from those of the geometric approximation. Together with the uncertainties of the spectral retrieval, the total relative error of the $\mathrm{H}_{2} \mathrm{O}$ VCD is defined as

$R_{\text {total }}=10 \%+a b s\left(\Delta \mathrm{O}_{4}\right)$.

Accoring to Eq. (8), the average error of the retrieved $\mathrm{H}_{2} \mathrm{O}$ VCDs is $24 \%$. Note that this error formula does not explicitly include the error caused by the wavelength dependence of the $\mathrm{H}_{2} \mathrm{O}$ AMF (see Sect. 2.3), which is significantly smaller.

\section{Comparison with independent data sets}

In this section, the $\mathrm{H}_{2} \mathrm{O}$ VCDs retrieved from the MAXDOAS observations are compared to other data sets:

a. $\mathrm{H}_{2} \mathrm{O}$ VCDs from the ERA-Interim reanalysis data set of the ECMWF; 
(mostly) clear day (23 March 2011)
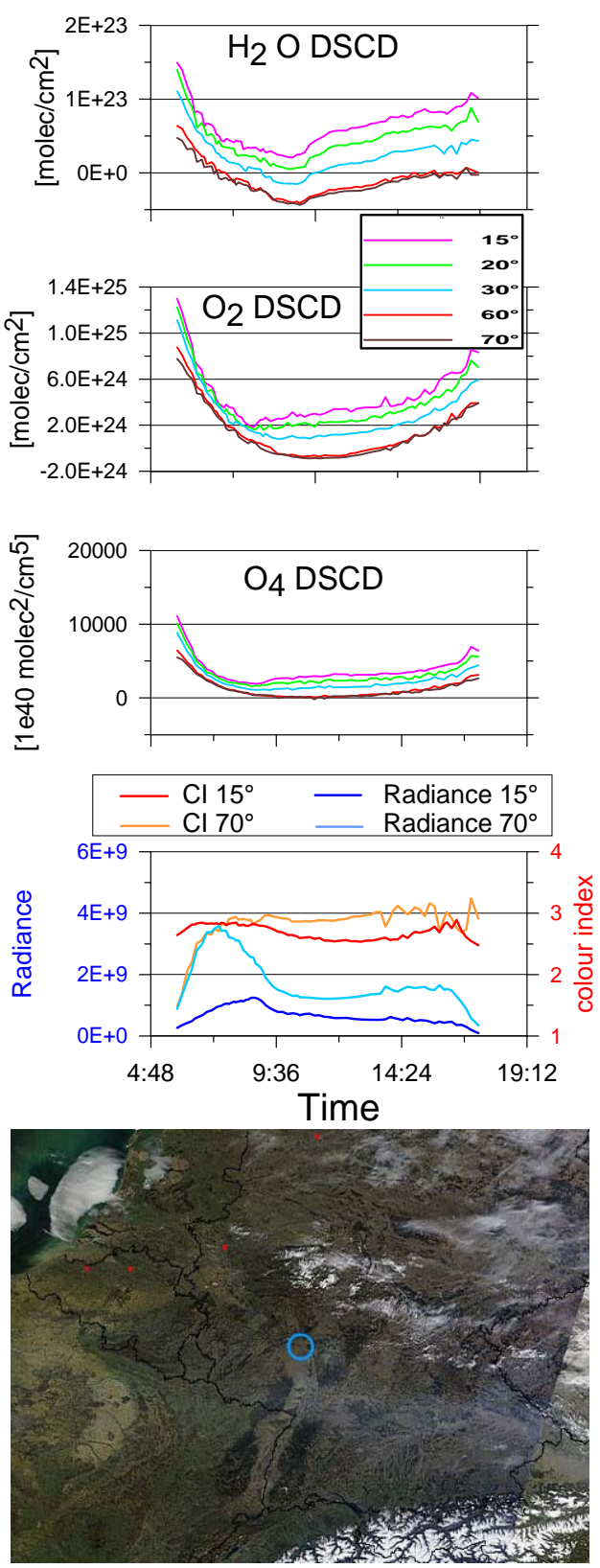

cloudy day (27 April 2011)
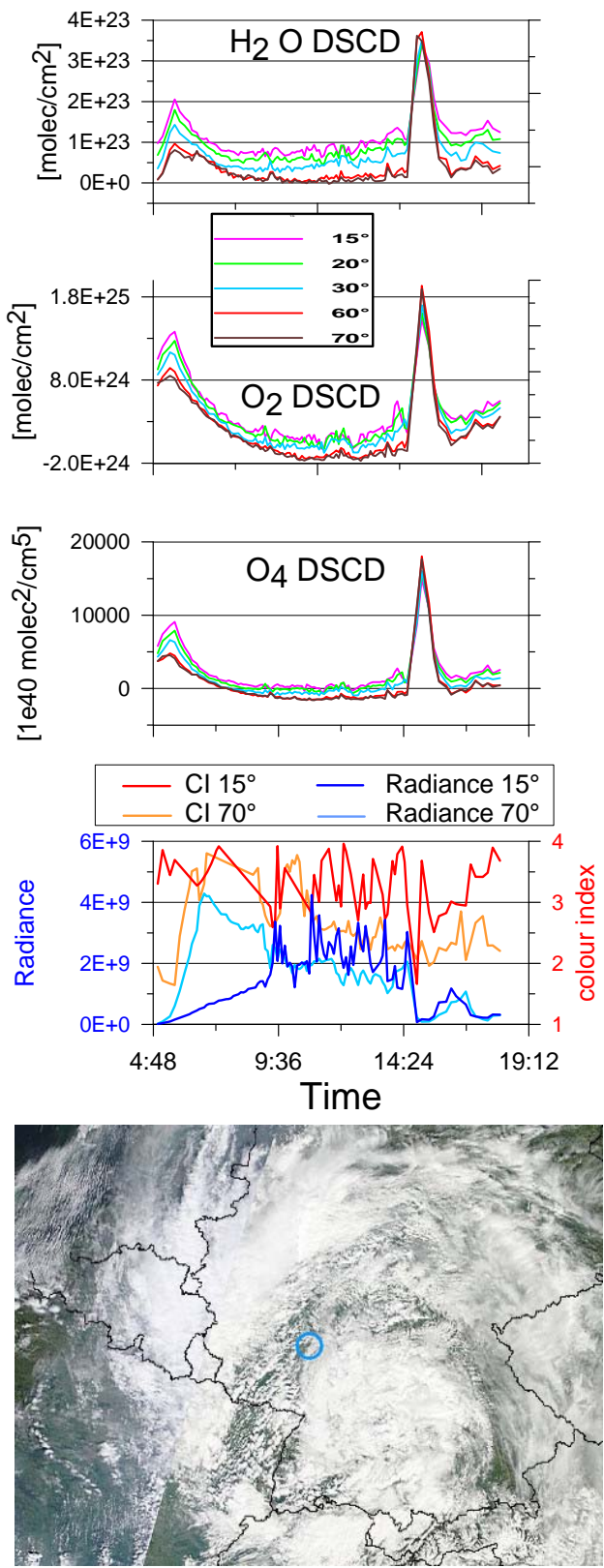

Fig. 10. Diurnal variation of the retrieved DSCDs of $\mathrm{H}_{2} \mathrm{O}, \mathrm{O}_{4}$ and $\mathrm{O}_{2}$ as well as the measured (relative) radiance and colour index for a mostly clear day (23 March 2011, left) and a mostly cloudy day (27 April 2011, right). In the bottom, satellite images from the MODIS instrument are shown. Note that for the DSCDs of $\mathrm{H}_{2} \mathrm{O}$ and $\mathrm{O}_{2}$ different y-scales for both days are used. The MODIS overpass times are 23 March 2011 at 11:00 LT; 27 April 2011 at 09:55 LT. (AERONET Data synergy tool, http://aeronet.gsfc.nasa.gov/cgi-bin/bamgomas_interactive).

b. $\mathrm{H}_{2} \mathrm{O}$ VCDs from AERONET measurements also made at MPIC, Mainz;

c. $\mathrm{H}_{2} \mathrm{O}$ VCDs from satellite observations of the GOME2 (Global ozone monitoring experiment) instrument on METOP (Meteorological operational platform); d. $\mathrm{H}_{2} \mathrm{O}$ surface concentrations measured by the air quality network of the federal state of Rhineland-Palatinate in a suburb of Mainz.

In the following subsections these data sets are briefly described, followed by a comparison of time series and correlation analyses. 
clear day (25 April 2011)

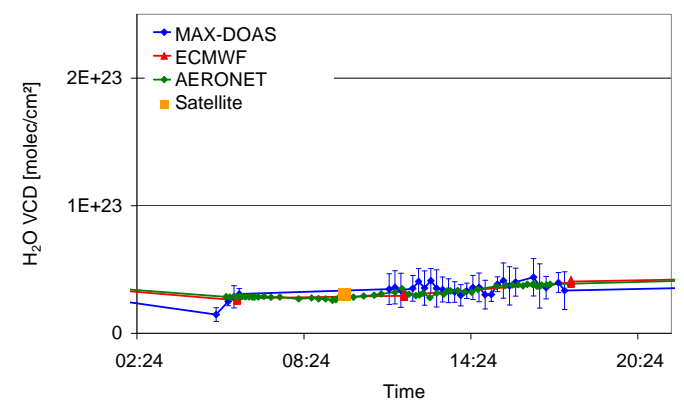

cloudy day (23 June 2011)

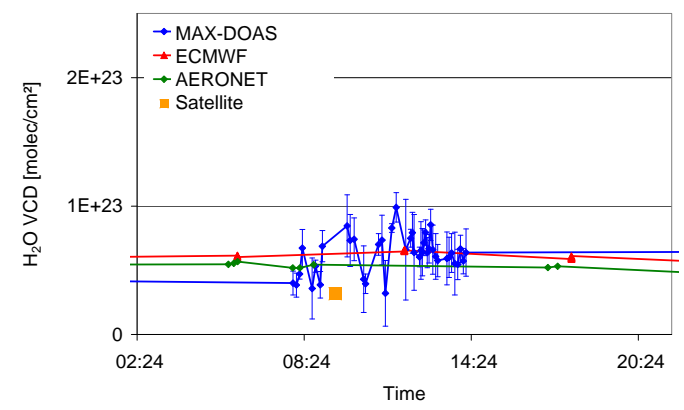

cloudy day (29 April 2011)

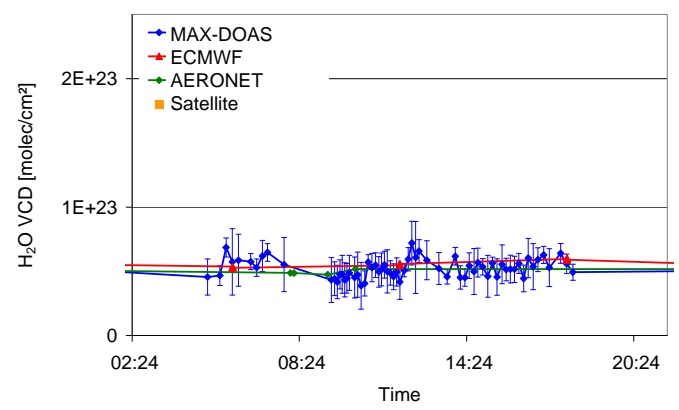

cloudy day (12 August 2011)

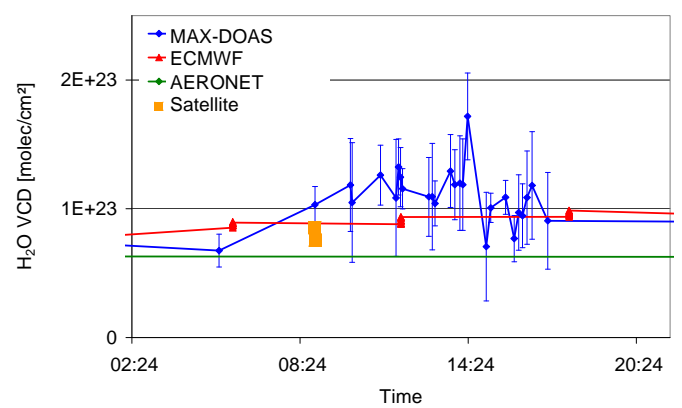

Fig. 11. Diurnal variation of the $\mathrm{H}_{2} \mathrm{O}$ VCD from the different data sets for selected days. The error bars of the MAX-DOAS data are calculated using Eq. (8). On the two cloudy days, in the bottom part of the figure, the scatter of the MAX-DOAS data is rather large indicating a strong cloud effect and/or rapid variation of the cloud properties. The increased scatter is well represented by the enhanced values of the error bars.

\subsection{ECMWF model data}

The $\mathrm{H}_{2} \mathrm{O}$ VCD simulation data used in this study are based on the total water column output of the ERA-Interim reanalysis data set (Dee et al., 2011) provided by the ECMWF. We used the output on a regular $0.25 / 0.25$ degree grid for every 6$\mathrm{h}$ model output between March and May 2011. For the comparison, the region between 7.75 and $8.25^{\circ} \mathrm{E}$ and between 49.75 and $50.25^{\circ} \mathrm{N}$ was averaged.

\subsection{AERONET observations}

$\mathrm{H}_{2} \mathrm{O}$ VCDs are retrieved from direct sun radiometry in the 940-nm solar absorption channel employed in the Aerosol Robotic Network (AERONET, http://aeronet.gsfc. nasa.gov/). The Mainz AERONET site at the MPIC is shown at http://aeronet.gsfc.nasa.gov/new_web/photo_db/ Mainz.html. Information on the AERONET observational network can be found in Holben et al. (2001). Details on the $\mathrm{H}_{2} \mathrm{O}$ retrieval are given, for example, in Schmid et al. (1996) and Smirnov et al. (2004).

In this study we use the Level 2.0 data. Typical integration times are 2 to $15 \mathrm{~min}$. AERONET direct sun measurements are even possible during rather short cloud-free periods. Here it is interesting to note that such conditions are often characterised as cloudy by our cloud algorithm (see Sect. 2.7), because they are associated with rapid fluctuations of the measured quantities. Since the MAX-DOAS retrieval of the $\mathrm{H}_{2} \mathrm{O}$ VCD is based on subsequent observations made at different elevation angles, under partly clear conditions the MAX-DOAS observations are more likely affected by clouds than the direct sun AERONET observations.

\subsection{Satellite observations}

Several $\mathrm{H}_{2} \mathrm{O}$ VCD products retrieved from UV-visible satellite instruments have been developed during the past years (Noël et al., 1999; Casadio et al., 2000; Maurellis et al., 2000; Lang et al., 2003; Wagner et al., 2003). In this study we use the retrieval developed at the University of Heidelberg and the MPIC (Wagner et al., 2003, 2006). Details of this retrieval are given in EUMETSAT (2009) (European organisation for the exploitation of meteorological satellites, http://atmos.caf. dlr.de/gome/product_h2o.html). This retrieval consists of two steps: first the slant column densities of $\mathrm{H}_{2} \mathrm{O}$ and $\mathrm{O}_{2}$ are analysed in the red part of the spectrum (614-682 nm). In a second step the $\mathrm{H}_{2} \mathrm{O}$ VCD is derived from the $\mathrm{H}_{2} \mathrm{O}$ SCD using a "measured" AMF based on the simultaneously measured $\mathrm{O}_{2} \mathrm{SCD}$. For the comparison with MAX-DOAS results, observations of the GOME-2 instrument on METOP are used, which cover the location of the MAX-DOAS instrument (EUMETSAT, 2005). GOME-2 has a ground pixel size of $80.40 \mathrm{~km}^{2}$, global coverage is achieved after 1.5 days. The overpass time of GOME- 2 is about 09:30 local time. The 

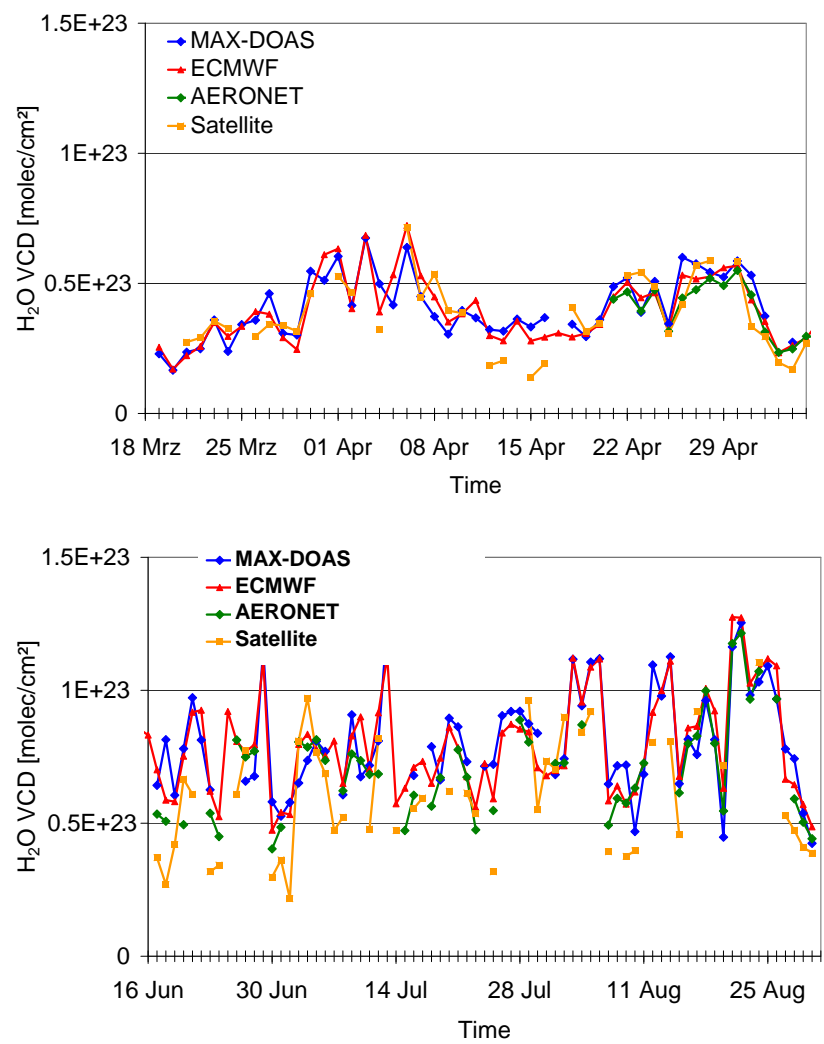

Fig. 12. Time series of daily average $\mathrm{H}_{2} \mathrm{O}$ VCDs derived from the different data sets. Top: first part of the MAX-DOAS measurements (19 March-4 April). Bottom: second part of the MAX-DOAS measurements (17 June-30 August).

satellite data are cloud screened by applying a threshold for the $\mathrm{O}_{2}$ absorption. It should, however, be noted that in individual cases, the shielding effect of clouds can still be substantial for the atmospheric $\mathrm{H}_{2} \mathrm{O}$ column.

\subsection{In situ observations}

Routine observations of temperature and relative humidity ( $1 \mathrm{~h}$ averages) are performed by the federal state of Rhineland-Palatinate in a suburb of Mainz, about $3.5 \mathrm{~km}$ north of the MAX-DOAS instrument (Landesamt für Umwelt, Wasserwirtschaft und Gewerbeaufsicht RheinlandPfalz, http://www.luft-rlp.de). Using the Clausius-Clapeyron relationship, we calculated the water vapour concentration from both measured quantities. Since these in situ observations provide the near-surface $\mathrm{H}_{2} \mathrm{O}$ concentration and not the $\mathrm{H}_{2} \mathrm{O}$ VCD, no direct comparison with the MAX-DOAS results is possible. Nevertheless, from the correlation analysis of both quantities, information on the agreement of the relative temporal variation can be obtained (see Sect. 3.6). In addition, the ratio of the $\mathrm{H}_{2} \mathrm{O}$ VCD and the $\mathrm{H}_{2} \mathrm{O}$ concentration can be determined, which provides information about the $\mathrm{H}_{2} \mathrm{O}$ scale height (see Sect. 3.7).

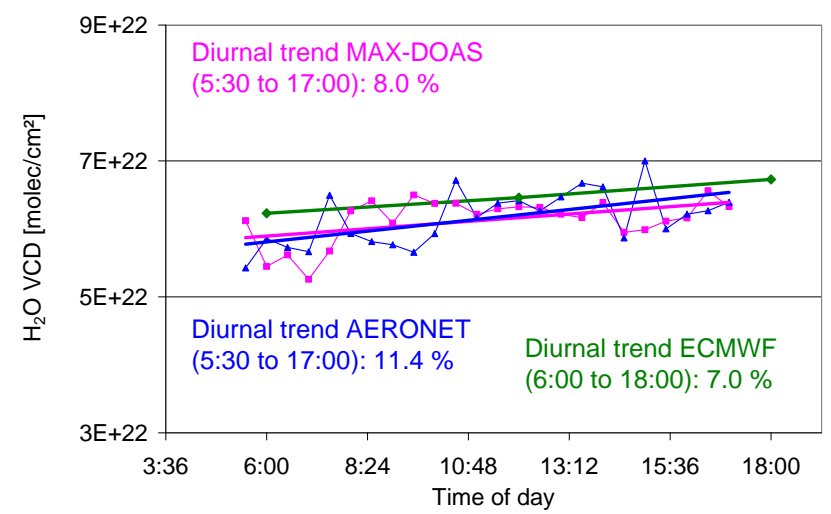

Fig. 13. Diurnal variation of $\mathrm{H}_{2} \mathrm{O}$ VCD derived from MAX-DOAS (pink), AERONET (blue) and ECMWF data (green). Data are averaged between 05:00 and 17:00 for all days, for which MAX-DOAS data are available.

Table 3. Results of selected correlation analyses between ECMWF data and the other data sets. Also the average ratios of individual data pairs $\langle A / B\rangle$ and $\langle A\rangle /\langle B\rangle$ are shown.

\begin{tabular}{|c|c|c|c|c|c|c|}
\hline Data sets & Quantity & Condition & $r^{2}$ & Slope & $\langle A / B\rangle$ & $\langle A\rangle /\langle B\rangle$ \\
\hline $\begin{array}{l}\text { ECMWF vs. } \\
\text { MAX-DOAS }\end{array}$ & $\mathrm{H}_{2} \mathrm{O}$ VCD & $\begin{array}{l}\text { Clear } \\
\text { according to } \\
\text { MAX-DOAS }\end{array}$ & 0.88 & 1.07 & 1.06 & 1.06 \\
\hline $\begin{array}{l}\text { ECMWF vs. } \\
\text { MAX-DOAS }\end{array}$ & $\mathrm{H}_{2} \mathrm{O}$ VCD & $\begin{array}{l}\text { Thin clouds } \\
\text { according to } \\
\text { MAX-DOAS }\end{array}$ & 0.88 & 1.05 & 0.98 & 0.98 \\
\hline $\begin{array}{l}\text { ECMWF vs. } \\
\text { MAX-DOAS }\end{array}$ & $\mathrm{H}_{2} \mathrm{O}$ VCD & $\begin{array}{l}\text { Thick clouds } \\
\text { according to } \\
\text { MAX-DOAS }\end{array}$ & 0.85 & 0.90 & 0.94 & 0.97 \\
\hline $\begin{array}{l}\text { ECMWF vs. } \\
\text { satellite }\end{array}$ & $\mathrm{H}_{2} \mathrm{O}$ VCD & $\begin{array}{l}\text { Clear } \\
\text { according to } \\
\text { satellite }\end{array}$ & 0.70 & 0.96 & 1.22 & 1.05 \\
\hline $\begin{array}{l}\text { ECMWF vs. } \\
\text { satellite }\end{array}$ & $\mathrm{H}_{2} \mathrm{O}$ VCD & $\begin{array}{l}\text { Clear } \\
\text { according to } \\
\text { MAX-DOAS }\end{array}$ & 0.83 & 0.91 & 1.04 & 0.99 \\
\hline $\begin{array}{l}\text { ECMWF vs. } \\
\text { satellite }\end{array}$ & $\mathrm{H}_{2} \mathrm{O}$ VCD & $\begin{array}{l}\text { Cloudy } \\
\text { according to } \\
\text { satellite }\end{array}$ & 0.40 & 1.70 & 1.70 & 1.51 \\
\hline $\begin{array}{l}\text { ECMWF vs. } \\
\text { AERONET }\end{array}$ & $\mathrm{H}_{2} \mathrm{O}$ VCD & & 0.93 & 1.03 & 1.07 & 1.07 \\
\hline $\begin{array}{l}\text { ECMWF vs. } \\
\text { in situ }\end{array}$ & $\begin{array}{l}\mathrm{H}_{2} \mathrm{O} \\
\text { concentration }\end{array}$ & & 0.90 & 1.01 & 1.01 & 1.00 \\
\hline
\end{tabular}

\subsection{Comparison of time series}

In Fig. 11, the diurnal variation of the $\mathrm{H}_{2} \mathrm{O}$ VCDs from the different data sets (MAX-DOAS, AERONET, satellite, ECMWF) is shown for selected days. For the MAX-DOAS data, error bars are also presented, which indicate the relative deviation of the retrieved $\mathrm{O}_{4}$ VCDs from the true value (see Sect. 2.5). The first day (25 April 2012) was a mainly clear day. The $\mathrm{H}_{2} \mathrm{O}$ VCDs retrieved from MAX-DOAS show only little scatter, and good agreement is found between all data sets. The second day (29 April 2012) was a mostly cloudy day, but again little scatter of the MAX-DOAS data and good agreement between all data sets is found (also the 

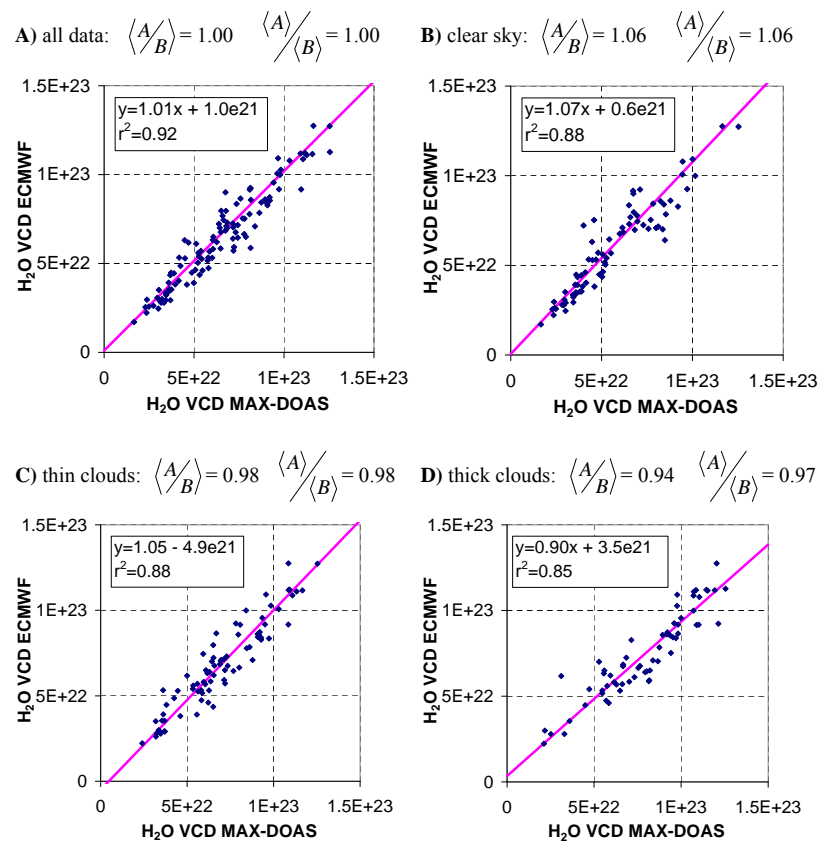

Fig. 14. Correlation analyses of daily average $\mathrm{H}_{2} \mathrm{O}$ VCDs from MAX-DOAS and ECMWF data. (A) All MAX-DOAS data. (B) MAX-DOAS observations for clear sky. (C) MAX-DOAS observations for thin clouds. (D) MAX-DOAS observations for thick clouds. ECMWF data are averages during daytime (06:00, 12:00, 18:00). The symbols $\left\langle\frac{A}{B}\right\rangle$ and $\frac{\langle A\rangle}{\langle B\rangle}$ indicate the average of ratios of individual data pairs and ratio of averages, respectively. All values in units of molec $\mathrm{cm}^{-2}$.

MAX-DOAS error bars are small). It should be noted that only few AERONET retrievals were possible on that day, because they can only be performed when the sun is visible. The third and fourth days were also mainly cloud covered. However, on these days the scatter of the MAX-DOAS data is larger than on the two first days, indicating that the cloud effects and/or their temporal variation were stronger. The increased scatter of the MAX-DOAS data is well reflected in the larger error bars. This indicates that the deviation of the measured $\mathrm{O}_{4} \mathrm{VCD}$ from the true value is a good measure for the accuracy of the $\mathrm{H}_{2} \mathrm{O}$ VCDs retrieved from MAX-DOAS. Also, the agreement with the other data sets is worse compared to the first two days.

In Fig. 12, the time series of daily averaged values of the $\mathrm{H}_{2} \mathrm{O}$ VCDs from the different data sets are shown. The first (19 March-4 May) and second part (17 June-30 August) of the measurement time series is displayed in two separate subplots. Overall, the agreement of the temporal patterns and the absolute values is good. However, especially for (partly) cloudy days the $\mathrm{H}_{2} \mathrm{O}$ VCDs retrieved from satellite observations are often lower than from the other data sets. This underestimation is mainly caused by the shielding effects of the atmospheric column below the clouds.

Figure 13 presents the diurnal variation of the hourly averaged $\mathrm{H}_{2} \mathrm{O}$ VCDs derived from MAX-DOAS, AERONET
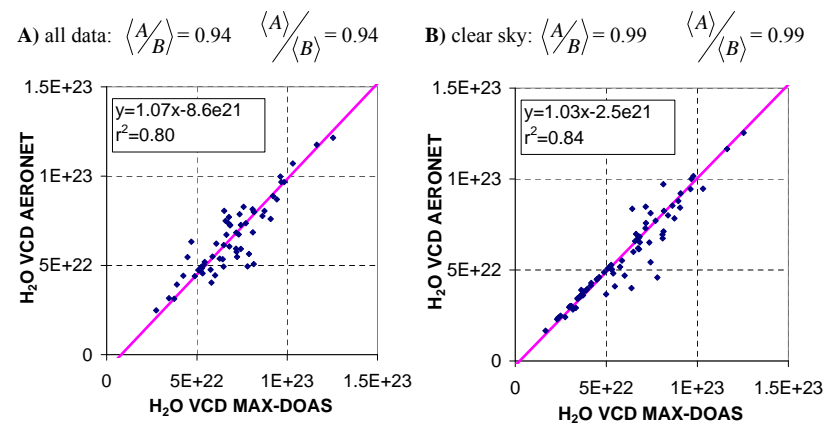

C) thin clouds: $\langle A / B\rangle=0.92 \quad\langle A\rangle /\langle B\rangle=0.93 \quad$ D) thick clouds: $\langle A / B\rangle=0.87 \quad\langle A\rangle /\langle B\rangle=0.85$
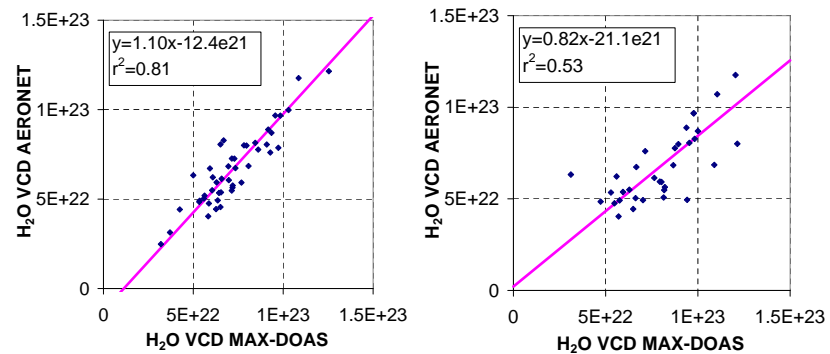

Fig. 15. Correlation analyses of daily average $\mathrm{H}_{2} \mathrm{O}$ VCDs from MAX-DOAS and AERONET data. (A) All MAX-DOAS data. (B) MAX-DOAS observations for clear sky. (C) MAX-DOAS observations for thin clouds. (D) MAX-DOAS observations for thick clouds. The symbols $\left\langle\frac{A}{B}\right\rangle$ and $\frac{\langle A\rangle}{\langle B\rangle}$ indicate the average of ratios of individual data pairs and ratio of averages, respectively. All values in units of molec $\mathrm{cm}^{-2}$.

and ECMWF data. Only measurements between 05:30 and 17:00 were chosen, because for this time period data are available for the whole duration of MAX-DOAS measurements. A systematic increase of the $\mathrm{H}_{2} \mathrm{O}$ VCD during the day is found in all data sets ranging from $7.0 \%$ (ECMWF) to $11.4 \%$ (AERONET) over a period of about $12 \mathrm{~h}$.

\subsection{Correlation analyses of daily average values}

In this section, correlation analyses using an orthogonal linear regression (Cantrell, 2008) for daily average values of the different data sets are presented and discussed. In addition to the results of the regression analyses, the ratios of the average values $\langle A\rangle /\langle B\rangle$ as well as the averages of the ratios $\langle A / B\rangle$ of individual data pairs are given. These quantities yield additional information about the agreement of the compared data sets.

Figure 14 presents the results for MAX-DOAS and ECMWF data. Overall good agreement is found with a coefficient of determination $\left(r^{2}\right)$ of 0.92 and a slope of 1.01. Similar results (but slightly higher slopes) are obtained if only MAX-DOAS observations for clear sky conditions or for thin clouds are considered. For MAX-DOAS observations under thick clouds the agreement is worse $\left(r^{2}=0.66\right)$. Also, the quantities $\langle A\rangle /\langle B\rangle$ and $\langle A / B\rangle$ show values close to unity. 

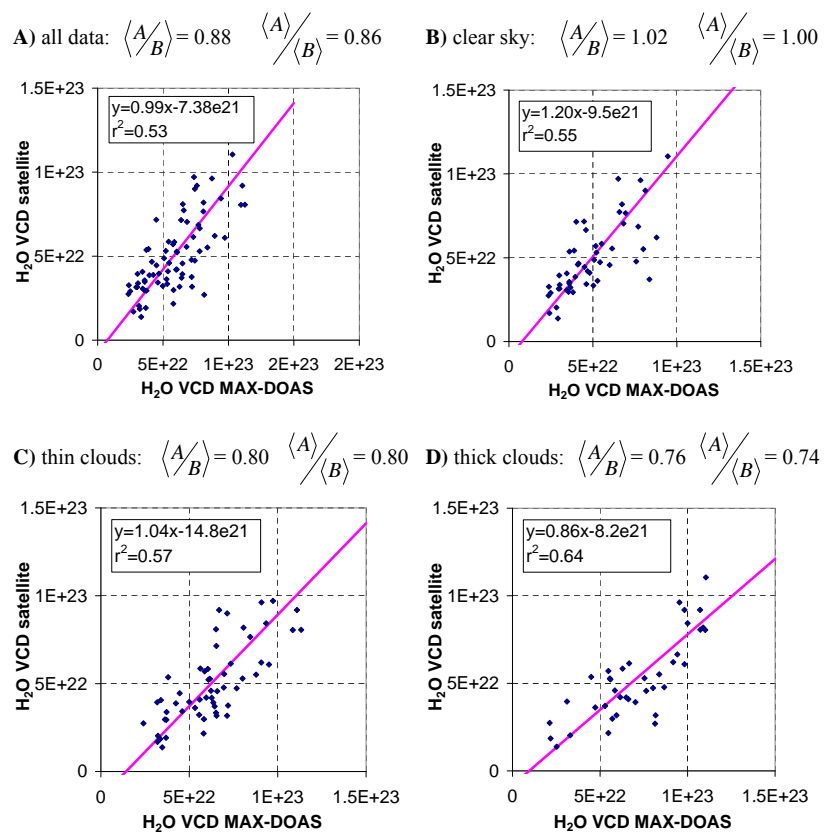

Fig. 16. Correlation analyses of daily average $\mathrm{H}_{2} \mathrm{O}$ VCDs from MAX-DOAS and satellite data. The satellite data include only measurements for mostly clear sky. (A) All MAX-DOAS data. (B) MAX-DOAS observations for clear sky. (C) MAX-DOAS observations for thin clouds. (D) MAX-DOAS observations for thick clouds. The symbols $\left\langle\frac{A}{B}\right\rangle$ and $\frac{\langle A\rangle}{\langle B\rangle}$ indicate the average of ratios of individual data pairs and ratio of averages, respectively. All values in units of molec $\mathrm{cm}^{-2}$.

In Fig. 15, results for the correlation analyses between MAX-DOAS and AERONET data are shown. Again, overall good agreement is found with a coefficient of determination $\left(r^{2}\right)$ of 0.80 and a slope of 1.07. If only MAX-DOAS data for clear sky conditions are considered, a better correlation $\left(r^{2}=0.84\right)$ is found, and if only MAX-DOAS data under thin clouds are considered, a slightly worse correlation $\left(r^{2}=0.81\right)$ is found. These findings are probably related to the fact that the AERONET $\mathrm{H}_{2} \mathrm{O}$ VCDs are retrieved from direct sunlight, which is not visible for cloudy conditions. For MAX-DOAS observations under thick clouds, only few coincident data pairs are available and the correlation is worse $\left(r^{2}=0.53\right)$. Again, the quantities $\langle A\rangle /\langle B\rangle$ and $\langle A / B\rangle$ show values close to unity (except for thick clouds).

In Fig. 16, results for the correlation analyses between MAX-DOAS and satellite data are shown. Compared to the previous comparisons, the correlation is worse $\left(r^{2}=0.53\right)$. This can mainly be attributed to the strong influence of clouds on the satellite data. Note that the satellite criterion for clear sky observations also includes measurements with small, but obviously not negligible cloud influence. Also, the quantities $\langle A\rangle /\langle B\rangle$ and $\langle A / B\rangle$ show larger deviations from unity than in the previous comparions. It might be interesting to note that on clear days, often MAX-DOAS
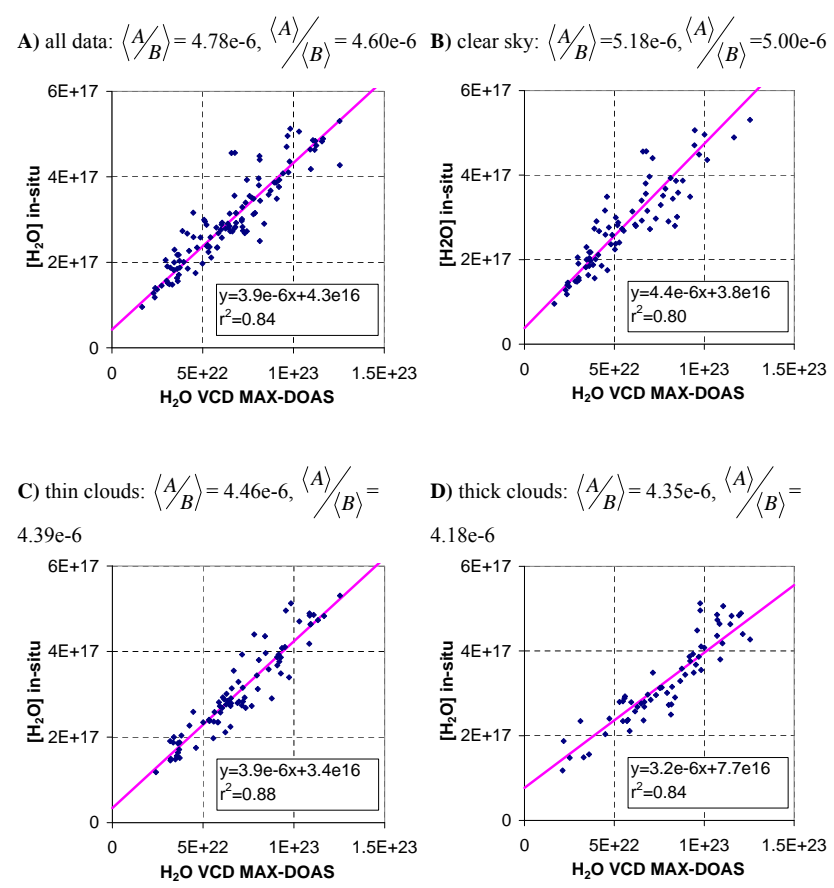

Fig. 17. Correlation analyses of daily average $\mathrm{H}_{2} \mathrm{O}$ VCDs from MAX-DOAS and the $\mathrm{H}_{2} \mathrm{O}$ concentration measured at the surface. (A) All MAX-DOAS data. (B) MAX-DOAS observations for clear sky. (C) MAX-DOAS observations for thin clouds. (D) MAXDOAS observations for thick clouds. The symbols $\left\langle\frac{A}{B}\right\rangle$ and $\frac{\langle A\rangle}{\langle B\rangle}$ indicate the average of ratios of individual data pairs and ratio of averages, respectively. $\mathrm{H}_{2} \mathrm{O}$ concentrations are in molec $\mathrm{cm}^{-3}$ and $\mathrm{H}_{2} \mathrm{O}$ VCDs in units of molec $\mathrm{cm}^{-2}$.

measurements in the mid morning (close to the satellite overpass) are skipped by the application of the $\mathrm{O}_{4}$ selection criterium, because for these observations the small RAZI can lead to strong errors of the geometric approximation (see Sect. 2.5). However, since the diurnal variation of the $\mathrm{H}_{2} \mathrm{O}$ VCD is on average small (see Fig. 13), this should have only a very small effect (a few percent) on the comparison between MAX-DOAS and satellite observations.

In Fig. 17, results for the correlation analyses between the $\mathrm{H}_{2} \mathrm{O}$ VCDs from MAX-DOAS and the $\mathrm{H}_{2} \mathrm{O}$ concentration measured at the surface are shown. Although different quantities are compared, a linear correlation can, in principle, be expected, because the overall shape of the water vapour concentration profile is mainly determined by the Clausius-Clapeyron relationship and the atmospheric lapse rate. This expectation is confirmed by the rather good correlation between both data sets $\left(r^{2}=0.84\right)$. Similar agreement is found for MAX-DOAS observations under clear skies and thin clouds. As in the previous examples, worse correlation is found for thick clouds $\left(r^{2}=0.54\right)$. Note that the quantities $\langle A\rangle /\langle B\rangle$ and $\langle A / B\rangle$ show systematically larger values than the slopes of the regression analyses, related to a positive $y$ axis intercept of the regression analysis. 


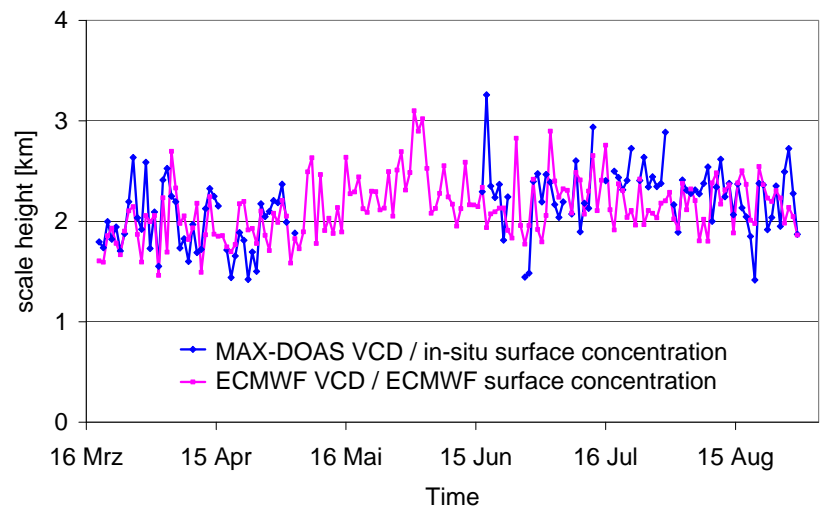

Fig. 18. $\mathrm{H}_{2} \mathrm{O}$ scale height calculated from the $\mathrm{H}_{2} \mathrm{O}$ VCD and the $\mathrm{H}_{2} \mathrm{O}$ concentration at the surface (Eq. 9). The blue curve shows values calculated from MAX-DOAS and in situ observations. The pink curve shows values calculated from ECMWF data.

Besides the correlation analyses between MAX-DOAS observations and the external data sets, correlation analyses between the different external data sets and ECMWF data were also performed. The results are summarised in Table 3 (including also the correlation results between ECMWF and MAX-DOAS). Very good correlation between AERONET and ECMWF $\left(r^{2}=0.93\right)$ as well as ECMWF and in situ data $\left(r^{2}=0.90\right)$ is found. For the comparison of ECMWF and satellite data the correlation is worse $\left(r^{2}=0.70\right)$. However, if only clear sky measurements (according to the MAX-DOAS observations) are selected, the correlation between ECMWF and satellite data improves again $\left(r^{2}=0.81\right)$, indicating that a substantial fraction of the satellite observations is affected by cloud shielding.

\subsection{Determination of $\mathrm{H}_{2} \mathrm{O}$ scale height}

From the MAX-DOAS $\mathrm{H}_{2} \mathrm{O}$ VCDs and the $\mathrm{H}_{2} \mathrm{O}$ concentration $\left[\mathrm{H}_{2} \mathrm{O}\right]$ measured at the surface, a characteristic height can be calculated:

$L=\frac{\mathrm{VCD}_{\mathrm{H}_{2} \mathrm{O}}}{\left[\mathrm{H}_{2} \mathrm{O}\right]}$.

$L$ can be interpreted as the scale height (i.e. the altitude at which the $\mathrm{H}_{2} \mathrm{O}$ concentration has decreased to $1 / e$ of the value at the surface) of an exponentially decreasing concentration. Such an exponential profile is not an unrealistic assumption because of the Clausius-Clapeyron relationship and the decreasing temperature with increasing altitude. In Fig. 18, the scale height $L$ derived from MAX-DOAS and in situ measurements is shown. In addition, the scale height calculated from the $\mathrm{H}_{2} \mathrm{O}$ VCD and the $\mathrm{H}_{2} \mathrm{O}$ surface concentration, both taken from the ECMWF model, is also shown. It shows good agreement with the scale height determined from MAX-DOAS and in situ observations. During the first part of the MAX-DOAS measurements slightly lower values are found (minimum: $1.5 \mathrm{~km}$, maximum: $2.8 \mathrm{~km}$ ) than during

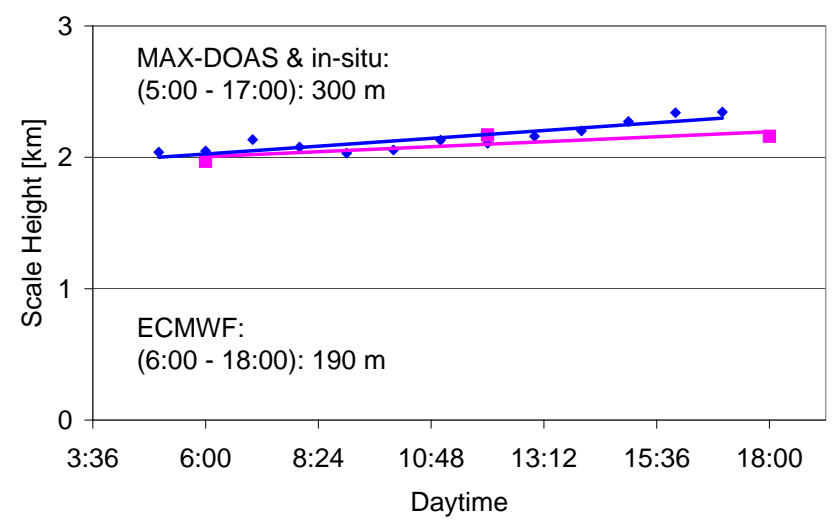

Fig. 19. Diurnal variation of hourly averaged scale heights derived from combined MAX-DOAS (blue) and in situ as well as ECMWF data (pink). Data are averaged between 05:00 and 17:00 for all days, for which MAX-DOAS data are available.

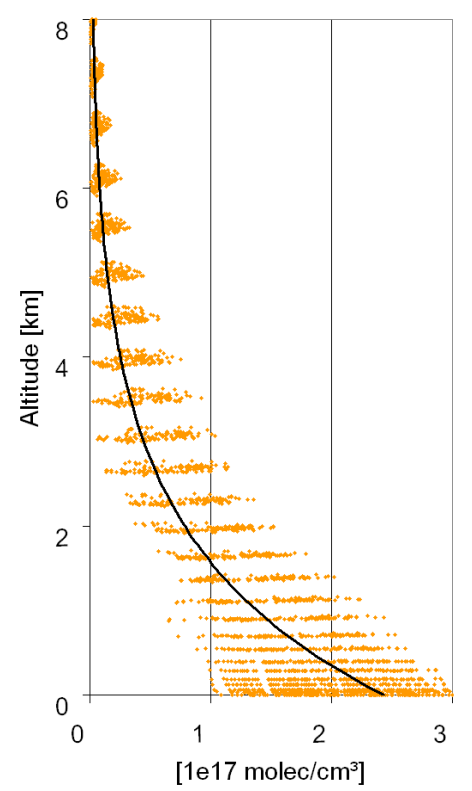

Fig. 20. $\mathrm{H}_{2} \mathrm{O}$ concentration profiles (from ECMWF data) above Mainz during June 2011. The black line represents an exponential fit to the data; the respective scale height is $1.77 \mathrm{~km}$.

the second part (minimum: $1.5 \mathrm{~km}$, maximum: $3.2 \mathrm{~km}$ ). The day-to-day variation is typically of the order of about $1 \mathrm{~km}$. The average scale height for all pairs of MAX-DOAS and in situ measurements is $2.15 \mathrm{~km}$. The respective average value for the ECMWF data is $2.08 \mathrm{~km}$. In spite of this good agreement for the average values, the day-to-day variation of the scale height is often different in both data sets $\left(r^{2}=0.13\right)$. For a few occasions, however, a strong diurnal variation of the scale height is simultaneously found in both data sets (e.g. an increase from about $1.5 \mathrm{~km}$ to $3.5 \mathrm{~km}$ on 5 May).

In Fig. 19, the average diurnal variation of the scale height derived from combined MAX-DOAS and in situ 
observations as well as from ECMWF data are shown. Both data sets show a systematic increase of about $300 \mathrm{~m}$ and $190 \mathrm{~m}$, respectively, during the day. From the time series of ECMWF data we find that the variation of the $\mathrm{H}_{2} \mathrm{O}$ scale height is typically $<1 \mathrm{~km}$ during one day (for $85 \%$ of all days during the MAX-DOAS measurements).

We investigated the profile shapes of the $\mathrm{H}_{2} \mathrm{O}$ concentration in more detail, based on the ECMWF data above Mainz, between March and August 2011. We fitted exponential functions to all profiles during the individual months (one example for June 2011 is shown in Fig. 20). The resulting scale heights vary between $1.6 \mathrm{~km}$ and $1.8 \mathrm{~km}$, and are, thus, systematically lower than the values calculated according to Eq. (9). This difference is mainly caused by the variability of the $\mathrm{H}_{2} \mathrm{O}$ concentration within the boundary layer, where the exponential fit is biased low. This causes the systematic deviations in the scale heights calculated from Eq. (9).

The calculation of the $\mathrm{H}_{2} \mathrm{O}$ scale height can be used as a simple quality indicator of the MAX-DOAS $\mathrm{H}_{2} \mathrm{O}$ VCD measurements: systematic errors of the retrieval will directly lead to unrealistic average $\mathrm{H}_{2} \mathrm{O}$ scale heights or diurnal variations. Improved future MAX-DOAS retrievals might allow the monitoring of the diurnal variation of the $\mathrm{H}_{2} \mathrm{O}$ scale height.

\section{Conclusions}

We developed an algorithm for the retrieval of the atmospheric water vapour column density from MAX-DOAS observations in the yellow and red spectral range. There the $\mathrm{H}_{2} \mathrm{O}$ absorption is much stronger than at shorter wavelengths, leading to increased sensitivity. Our algorithm is based on measurements from only two elevation angles, and, thus, has the potential to yield a rather high temporal resolution (of the order of minutes or less). The retrieval is based on the application of the simple geometric approximation and does not depend on explicit a priori information for individual observations, extensive radiative transfer simulations, or the construction of large look-up tables. Disturbances of the radiative transfer due to aerosols and clouds are simply corrected using the simultaneously measured $\mathrm{O}_{4}$ absorptions. The measured $\mathrm{O}_{4}$ absorption is also used to quantify the measurement errors. In addition to the $\mathrm{H}_{2} \mathrm{O}$ retrieval, we also developed a simple cloud characterisation scheme based on quantities derived from the MAX-DOAS observations.

We applied our retrieval scheme to MAX-DOAS observations made at the Max Planck Institute for Chemistry in Mainz, Germany, from March to August 2011. MAX-DOAS measurements were performed and analysed for about 40000 single measurements made on 111 days.

We compared the $\mathrm{H}_{2} \mathrm{O}$ VCDs retrieved from the MAXDOAS observations with independent data sets on the basis of daily averages. In addition to the $\mathrm{H}_{2} \mathrm{O}$ VCDs from AERONET measurements, satellite observations, and
ECMWF model simulations, $\mathrm{H}_{2} \mathrm{O}$ concentrations measured at the surface were also considered. Good agreement with AERONET and ECMWF $\mathrm{H}_{2} \mathrm{O}$ VCDs was found with coefficients of determination $\left(r^{2}\right)$ between 0.80 and 0.92 and regression slopes between 1.01 and 1.10 (except for thick clouds). For the comparison with ECMWF data, the agreement for MAX-DOAS observations under thin clouds and clear sky conditions is very similar. This indicates that our algorithm is well suited for observations under cloudy skies (except optically thick clouds). For the comparison with AERONET data, the agreement for observations under clear sky conditions is substantially better than for cloudy observations, mainly because AERONET observations are only possible if direct sunlight can be observed.

For the comparison with satellite observations, the agreement found is not as good $\left(r^{2}\right.$ between 0.53 and 0.64 , slopes of the regression lines between 0.86 and 1.20); underestimation of the satellite data can be mainly attributed to the shielding effect of clouds.

For the comparison with the $\mathrm{H}_{2} \mathrm{O}$ concentration measured at the surface good correlation was found $\left(r^{2}\right.$ between 0.84 and 0.88 ), but a quantitative comparison of the different quantities would require profile information. Nevertheless, from the time series of MAX-DOAS $\mathrm{H}_{2} \mathrm{O}$ VCDs and the $\mathrm{H}_{2} \mathrm{O}$ surface concentration we derived a characteristic layer height (scale height). Typical values are between 1.5 and $3 \mathrm{~km}$, the average value during the whole time series is $2.1 \mathrm{~km}$. Good agreement with scale heights calculated from ECMWF data is found. From the combined MAX-DOAS and in situ observations as well as from ECMWF data, an increase of the $\mathrm{H}_{2} \mathrm{O}$ scale height during the day is found (between $190 \mathrm{~m}$ and $300 \mathrm{~m}$ during $12 \mathrm{~h}$ ). During the same period, an average increase of the $\mathrm{H}_{2} \mathrm{O}$ VCD between $7 \%$ (ECMWF) and $11.4 \%$ (AERONET) is found (the respective increase of MAX-DOAS $\mathrm{H}_{2} \mathrm{O}$ VCD is $8 \%$ ).

MAX-DOAS observations of the $\mathrm{H}_{2} \mathrm{O}$ VCD use inexpensive and simple instrumentation, which can be operated automatically. Our retrieval algorithm is fast and robust and can yield the $\mathrm{H}_{2} \mathrm{O} V C D$ and associated uncertainties in near real-time, even under cloudy conditions (except for optically thick clouds). In addition to the $\mathrm{H}_{2} \mathrm{O} \mathrm{VCD}$, other trace gases (e.g. $\mathrm{NO}_{2}$ ) or aerosol properties can in principle be simultaneously retrieved from the MAX-DOAS observations. In the future, MAX-DOAS measurements should use optimised viewing angles: zenith observations should be included, and small RAZI should be avoided (the telescope should be directed to the north in the Northern Hemisphere). Here it should be noted that for each combination of elevation angles, appropriate correction factors (Eq. 5) have to be calculated and applied. Interestingly, for combinations of typical low $\left(15^{\circ}\right.$ to $\left.30^{\circ}\right)$ and high elevation angles $\left(60^{\circ}\right.$ to $\left.90^{\circ}\right)$ only rather small variations $( \pm 5 \%)$ of the correction factor are found. 
Acknowledgements. We used several external data sets in this study and we want to thank especially the following persons and institutions: MODIS images were obtained from NASA/GSFC, MODIS Rapid Response, http://aeronet.gsfc.nasa.gov/cgi-bin/bamgomas_interactive.

Surface $\mathrm{H}_{2} \mathrm{O}$ concentrations and $\mathrm{H}_{2} \mathrm{O}$ VCDs from the ERAInterim reanalysis data set provided by the European Centre for Medium-Range Weather Forecasts. In situ measurements of surface-near temperature and relative humidity were performed by the Landesamt für Umwelt, Wasserwirtschaft und Gewerbeaufsicht, Abt. 6, Kaiser-Friedrich-Straße 755116 Mainz (http://www.luft-rlp.de/aktuell/messwerte/). We thank Tracey W. Andreae for help with the preparation of the manuscript and Günther Schebeske for operating the AERONET instrument at the Max Planck Institute for Chemistry.

The service charges for this open access publication have been covered by the Max Planck Society.

Edited by: D. Brunner

\section{References}

Bobrowski, N., Hönninger, G., Galle, B., and Platt, U.: Detection of bromine monoxide in a volcanic plume, Nature, 423, 273-276, 2003.

Brinksma, E. J., Pinardi, G., Braak, R., Volten, H., Richter, A., Schönhardt, A., van Roozendael, M., Fayt, C., Hermans, C., Dirksen, R. J., Vlemmix, T., Berkhout, A. J. C., Swart, D. P. J., Ötjen, H., Wittrock, F., Wagner, T., Ibrahim, O. W., de Leeuw, G., Moerman, M., Curier, R. L., Celarier, E. A., Knap, W. H., Veefkind, J. P., Eskes, H. J., Allaart, M., Rothe, R., Piters, A. J. M., and Levelt, P. F.: The 2005 and 2006 DANDELIONS $\mathrm{NO}_{2}$ and Aerosol Validation Campaigns, J. Geophys. Res., 113, D16S46, doi:10.1029/2007JD008808, 2008.

Burrows, J. P., Dehn, A., Deters, B., Himmelmann, S., Richter, A., Voigt, S., and Orphal, J.: Atmospheric Remote-Sensing Reference Data from GOME: 2. Temperature-Dependent Absorption Cross Sections of $\mathrm{O}_{3}$ in the 231-794 nm Range, J. Quant. Spectrosc. Ra., 61, 509-517, 1999.

Cantrell, C. A.: Technical Note: Review of methods for linear leastsquares fitting of data and application to atmospheric chemistry problems, Atmos. Chem. Phys., 8, 5477-5487, doi:10.5194/acp8-5477-2008, 2008.

Casadio, S., Zehner, C., Pisacane, G., and Putz, E.: Empirical retrieval of the atmospheric air mass factor (ERA) for the measurement of water vapour vertical content using GOME data, Geophys. Res. Lett., 27, 1483-1486, 2000.

Dee, D. P., Uppala, S. M., Simmons, A. J., Berrisford, P., Poli, P., Kobayashi, S., Andrae, U., Balmaseda, M. A., Balsamo, G., Bauer, P., Bechtold, P., Beljaars, A. C. M., van de Berg, L., Bidlot, J., Bormann, N., Delsol, C., Dragani, R., Fuentes, M., Geer, A. J., Haimberger, L., Healy, S. B., Hersbach, H., Hólm, E. V., Isaksen, L., Kållberg, P., Köhler, M., Matricardi, M., McNally, A. P., Monge-Sanz, B. M., Morcrette, J.-J., Park, B.-K., Peubey, C., de Rosnay, P., Tavolato, C., Thépaut, J.-N., and Vitart, F.: The ERA-Interim reanalysis: configuration and performance of the data assimilation system, Q. J. Roy. Meteorol. Soc., 137, 553597, doi:10.1002/qj.828, 2011.
Deutschmann, T., Beirle, S., Frieß, U., Grzegorski, M., Kern, C., Kritten, L., Platt, U., Pukite, J., Wagner, T., Werner, B., and Pfeilsticker, K.: The Monte Carlo Atmospheric Radiative Transfer Model McArtim: Introduction and Validation of Jacobians and 3D Features, J. Quant. Spectrosc. Ra., 112, 1119-1137, doi:10.1016/j.jqsrt.2010.12.009, 2011.

EUMETSAT: GOME-2 Products Guide, available at: http:// oiswww.eumetsat.org/WEBOPS/eps-pg/GOME-2/ (last access: 29 January 2013), 2005.

EUMETSAT: Algorithm Theoretical Basis Document for GOME2 Total Column Products of Ozone, $\mathrm{NO}_{2}$, tropospheric $\mathrm{NO}_{2}$, $\mathrm{BrO}, \mathrm{SO}_{2}, \mathrm{H}_{2} \mathrm{O}, \mathrm{HCHO}, \mathrm{OclO}$ and Cloud Properties, Algorithm Theoretical Basis Document, available at: http://atmos.caf.dlr. de/gome2/docs/DLR_GOME-2_ATBD.pdf (last access: 29 January 2013), 2009.

Erle, F., Pfeilsticker, K., and Platt, U.: On the influence of tropospheric clouds on zenith scattered light measurements of stratospheric species, Geophys. Res. Lett., 22, 2725-2728, 1995.

Fayt, C. and Van Roozendael, M.: WinDOAS 2.1 Software User Manual, available at: http://www.oma.be/BIRA-IASB/ Molecules/BrO/WinDOAS-SUM-210b.pdf (last access: 29 January 2013), 2001.

Greenblatt, G. D., Orlando, J. J., Burkholder, J. B., and Ravishankara, A. R.: Absorption measurements of oxygen between 330 and 1140 nm, J. Geophys. Res., 95, 18577-18582, 1990.

Held, I. M. and Soden, B. J.: Water vapour feedback and global warming, Annu. Rev. Energ. Env., 25, 441-475, 2000.

Holben, B. N., Tanre, D., Smirnov, A., Eck, T. F., Slutsker, I., Abuhassan, N., Newcomb, W. W., Schafer, J., Chatenet, B., Lavenue, F., Kaufman, Y. J., Vande Castle, J., Setzer, A., Markham, B., Clark, D., Frouin, R., Halthore, R., Karnieli, A., O’Neill, N. T., Pietras, C., Pinker, R. T., Voss, K., and Zibordi, G.: An emerging ground-based aerosol climatology: Aerosol Optical Depth from AERONET, J. Geophys. Res., 106, 12067-12097, 2001.

Hönninger, G. and Platt, U.: Observations of $\mathrm{BrO}$ and its vertical distribution during surface ozone depletion at Alert, Atmos. Environ., 36, 2481-2490, 2002.

Ibrahim, O., Shaiganfar, R., Sinreich, R., Stein, T., Platt, U., and Wagner, T.: Car MAX-DOAS measurements around entire cities: quantification of $\mathrm{NO}_{\mathrm{x}}$ emissions from the cities of Mannheim and Ludwigshafen (Germany), Atmos. Meas. Tech., 3, 709-721, doi:10.5194/amt-3-709-2010, 2010.

Irie, H., Takashima, H., Kanaya, Y., Boersma, K. F., Gast, L., Wittrock, F., Brunner, D., Zhou, Y., and Van Roozendael, M.: Eightcomponent retrievals from ground-based MAX-DOAS observations, Atmos. Meas. Tech., 4, 1027-1044, doi:10.5194/amt-41027-2011, 2011.

Kraus, S.: DOASIS, A Framework Design for DOAS, PhDthesis, University of Mannheim, available at: http://hci.iwr. uni-heidelberg.de/publications/dip/2006/Kraus_PhD2006.pdf (last access: 29 January 2013), 2006.

Kurucz, R. L., Furenlid, I., Brault, J., and Testerman, L.: Solar flux atlas from $296 \mathrm{~nm}$ to $1300 \mathrm{~nm}$, National Solar Observatory Atlas No. 1, Office of University publisher, Harvard University, Cambridge, 1984.

Lang, R., Williams, J. E., van der Zande, W. J., and Maurellis, A. N.: Application of the Spectral Structure Parameterization technique: retrieval of total water vapor columns from GOME, Atmos. Chem. Phys., 3, 145-160, doi:10.5194/acp-3-145-2003, 
2003.

Maurellis, A. N., Lang, R., van der Zande, W. J., Aben, I., and Ubachs, W.: Precipitable Water Column Retrieval from GOME data, Geophys. Res. Lett., 27, 903-906, 2000.

Noël, S., Buchwitz, M., Bovensmann, H., Hoogen, R., and Burrows, J. P.: Atmospheric Water Vapour Amounts Retrievd from GOME Satellite data, Geophys. Res. Lett., 26, 1841-1844, 1999.

Platt, U. and Stutz, J.: Differential Optical Absorption Spectroscopy, Principles and Applications, Springer, Berlin, 2008.

Puķite, J., Kühl, S., Deutschmann, T., Platt, U., and Wagner, T.: Extending differential optical absorption spectroscopy for limb measurements in the UV, Atmos. Meas. Tech., 3, 631-653, doi:10.5194/amt-3-631-2010, 2010.

Rothman, L. S., Jacquemart, D., Barbe, A., Benner, D. C., Birk, M., Brown, L. R., Carleer, M. R., Chackerian Jr., C., Chance, K., Coudert, L. H., Dana, V., Devi, V. M., Flaud, J.-M., Gamache, R. R., Goldman, A., Hartmann, J.-M., Jucks, K. W., Maki, A. G., Mandin, J.-Y., Massie, S. T., Orphal, J., Perrin, A., Rinsland, C. P., Smith, M. A. H., Tennyson, J., Tolchenov, R. N., Toth, R. A., Vander Auwera, J., Varanasi, P., and Wagner, G.: The HITRAN 2004 molecular spectroscopic database, J. Quant. Spectrosc. Ra., 96, 139-204, 2005.

Schmid, B., Thome, K. J., Demoulin, P., Peter, R., Matzler, C., and Sekler, J.: Comparison of modeled and empirical approaches for retrieving columnar water vapour from solar transmittance measurements in the 0.94 micron region, J. Geophys. Res., 101, 9345-9358, 1996.

Shaiganfar, R., Beirle, S., Sharma, M., Chauhan, A., Singh, R. P., and Wagner, T.: Estimation of $\mathrm{NO}_{\mathrm{x}}$ emissions from Delhi using Car MAX-DOAS observations and comparison with OMI satellite data, Atmos. Chem. Phys., 11, 10871-10887, doi:10.5194/acp-11-10871-2011, 2011.

Smirnov, A., Holben, B. N., Lyapustin, A., Slutsker, I., and Eck, T. F.: AERONET processing algorithms refinement. Proc. AERONET Workshop, El Arenosillo, Spain, NASA/GSFC Aeronet Project, 2004.

Solomon, S., Qin, D., Manning, M., Alley, R. B., Berntsen, T., Bindoff, N. L., Chen, Z., Chidthaisong, A., Gregory, J. M., Hegerl, G. C., Heimann, M., Hewitson, B., Hoskins, B. J., Joos, F., Jouzel, J., Kattsov, V., Lohmann, U., Matsuno, T., Molina, M., Nicholls, N., Overpeck, J., Raga, G., Ramaswamy, V., Ren, J., Rusticucci, M., Somerville, R., Stocker, T. F., Whetton, P., Wood, R. A., and and Wratt, D.: Technical Summary, in: Climate Change 2007: The Physical Science Basis. Contribution of Working Group I to the Fourth Assessment Report of the Intergovernmental Panel on Climate Change edited by: Solomon, S., Qin, D., Manning, M., Chen, Z., Marquis, M., Averyt, K. B., Tignor, M., and Miller, H. L., Cambridge University Press, Cambridge, United Kingdom and New York, NY, USA, 2007.
Van Roozendael, M., Fayt, C., Post, P., Hermans, C., and Lambert, J.-C.: Retrieval of $\mathrm{BrO}$ and $\mathrm{NO}_{2}$ from UV-Visible Observations, in: Sounding the troposphere from space: a new era for atmospheric chemistry, edited by: Borrell, P. M., Burrows, J. P., and Platt, U., Springer, Heidelberg, ISBN 3-540-40873-8, 2003.

Wagner, T., Erle, F., Marquard, L., Otten, C., Pfeilsticker, K., Senne, T., Stutz, J., and Platt, U.: Cloudy sky optical paths as derived from differential optical absorption spectroscopy observations, J. Geophys. Res., 103, 25307-25321, 1998.

Wagner, T., Heland, J., Zöger, M., and Platt, U.: A fast $\mathrm{H}_{2} \mathrm{O}$ total column density product from GOME - Validation with insitu aircraft measurements, Atmos. Chem. Phys., 3, 651-663, doi:10.5194/acp-3-651-2003, 2003.

Wagner, T., Dix, B., Friedeburg, C. V., Frieß, U., Sanghavi, S., Sinreich, R., and Platt, U.: MAX-DOAS $\mathrm{O}_{4}$ measurements - a new technique to derive information on atmospheric aerosols. (I) Principles and information content, J. Geophys. Res., 109, D22205, doi:10.1029/2004JD004904, 2004.

Wagner, T., Beirle, S., Grzegorski, M., and Platt, U.: Global trends (1996-2003) of total column precipitable water observed by Global Ozone Monitoring Experiment (GOME) on ERS-2 and their relation to near-surface temperature, J. Geophys. Res., 111, D12102, doi:10.1029/2005JD006523, 2006.

Wagner, T., Ibrahim, O., Shaiganfar, R., and Platt, U.: Mobile MAX-DOAS observations of tropospheric trace gases, Atmos. Meas. Tech., 3, 129-140, doi:10.5194/amt-3-129-2010, 2010.

Wagner, T., Beirle, S., Brauers, T., Deutschmann, T., Frieß, U., Hak, C., Halla, J. D., Heue, K. P., Junkermann, W., Li, X., Platt, U., and Pundt-Gruber, I.: Inversion of tropospheric profiles of aerosol extinction and $\mathrm{HCHO}$ and $\mathrm{NO}_{2}$ mixing ratios from MAX-DOAS observations in Milano during the summer of 2003 and comparison with independent data sets, Atmos. Meas. Tech., 4, 2685-2715, doi:10.5194/amt-4-2685-2011, 2011.

Wagner, T., Andreae, M. O., Beirle, S., Dörner, S., Mies, K., and Shaiganfar, R.: MAX-DOAS observations of the total atmospheric water vapour column and comparison with independent observations, Atmos. Meas. Tech. Discuss., 5, 6241-6283, doi:10.5194/amtd-5-6241-2012, 2012.

Winterrath, T., Kurosu, T. P., Richter, A., and Burrows, J. P.: Enhanced $\mathrm{O}_{3}$ and $\mathrm{NO}_{2}$ in thunderstorm clouds: convection or production?, Geophys. Res. Lett., 26, 1291-1294, 1999.

Wittrock, F., Oetjen, H., Richter, A., Fietkau, S., Medeke, T., Rozanov, A., and Burrows, J. P.: MAX-DOAS measurements of atmospheric trace gases in Ny-Ålesund - Radiative transfer studies and their application, Atmos. Chem. Phys., 4, 955-966, doi:10.5194/acp-4-955-2004, 2004. 